\title{
Confining Isolated Atoms and Clusters in Crystalline Porous Materials for \\ Catalysis
}

\author{
Lichen Liu and Avelino Corma* \\ Instituto de Tecnología Química, Universidad Politécnica de Valencia-Consejo Superior de \\ Investigaciones Científicas (UPV-CSIC), Av. de los Naranjos s/n, 46022 Valencia, Spain \\ *corresponding author. Email: acorma@itq.upv.es
}

\begin{abstract}
The recent works on supported isolated metal atoms and metal clusters with a few atoms have reformed our understanding on the structure-reactivity relationship established on conventional nanoparticulate catalysts. One critical issue related to supported subnanometric metal catalysts (including both isolated atoms and clusters) on conventional open-structure carriers is the stability of the metal entities, since they may sinter into large nanoparticles under harsh reaction conditions. By confining the isolated metal atoms or subnanometric metal clusters in crystalline porous materials (such as zeolites and metal-organic frameworks) can improve the stability of these tiny species against sintering into nanoparticles. More importantly, the interaction between the metal species and the porous framework may modulate the geometric and electronic structures of the subnanometric metal species, especially in the cases of metal clusters. Such confinement effect can induce shape-selective catalysis or unique chemoselectivity compared to the counterpart metal entities supported on conventional open-structure solid carriers. In this review, we will discuss the structural features, synthesis methodologies, characterization techniques and catalytic applications of subnanometric species confined in zeolites and metal-organic frameworks, aiming to make critical comparison between confined and un-confined isolated atoms and metal clusters and to give perspectives on the future developments.
\end{abstract}




\section{Introduction}

The recent progress in heterogeneous catalysis based on isolated atoms and metal clusters with a few atoms has enriched our previous understanding on structure-reactivity relationships based on conventional nanoparticulate metal catalysts ${ }^{1-3}$. Indeed, the interaction between the metal sites and reactant molecules, and the corresponding catalytic behaviour of isolated atoms and metal clusters are distinct to their nanoparticulate counterparts due to their unique electronic and geometric structures ${ }^{4-7}$. It has been demonstrated in various systems that, the reactivity of isolated atoms and subnanometric clusters are strongly dependent on the solid supports or the ligands surrounding them. By decreasing the size of the metal species from nanometre scale to subnanometric regime, the increased exposed metal surface area and geometry of active sites has nucleated plenty of new experimental phenomena and mechanistic insights on catalysis.

However, the stability of isolated atoms and metal clusters towards agglomeration under reductionoxidation atmosphere or under reaction conditions, is a key issue that can limit their practical applications for industrial processes, or even can induce to misinterpretation of the results as far as the nature of the catalytically active sites is concerned ${ }^{8,9}$. We will discuss here the incorporation of isolated metal atoms or nanoclusters into crystalline microporous materials such as zeolites and metal-organic framework (MOF) materials, going beyond the most intuitive particle size limitation and sintering problem ${ }^{10-12}$. Indeed, one can also explore the specific advantages introduced by nanoporous materials, such as selecting a given reactant among a mixture owing to molecular sieving effects, as well as the stabilization of reaction transition states, together with collaborative effects between the crystalline porous framework and the isolated metal atoms and clusters. This last effect will imply changes in the electronic structure of the metal entities due to the multi-dimensional interactions with the wall of the nanopores, as well as the preferential stabilization of certain configuration of cluster structure among various thermodynamically possibilities. Such interactions between the metal species and the crystalline porous structure will be reflected in their catalytic reactivity, selectivity and stability under reaction conditions.

Starting from the geometric and electronic structures of isolated atoms and clusters confined in zeolites and MOFs, the behaviour of subnanometric metal species in confined and unconfined environment will be compared. We will discuss the characterization techniques used to study the structures of those metal entities at atomic and molecular level. Moreover, some important catalytic applications of subnanometric 
metal species confined in crystalline porous materials will be summarised and structure-reactivity correlation will be made according to the catalytic outcomes. Finally, perspectives on the future developments in this field will be given with emphasis on how to deepen our fundamental understanding on the structures and catalytic behaviour of those materials, in order to push them towards practical applications.

\section{Structure of confined metal species}

\subsection{Isolated atoms in confined space}

When a single metal atom is supported on conventional solid carriers, such as carbon, metal oxide, metal sulphide, carbide and MXene, the metal atom usually occupies a vacancy position surrounded by heteroatoms (such as $\mathrm{O}, \mathrm{N}, \mathrm{S}, \mathrm{P}$ etc) and the geometric structure of the single-atom species depends on the arrangement of atoms on the surface (see Figure 1 and Box 1$)^{13-15}$. The metal atoms usually locate in the defect sites with coordination interaction from electron-donor atoms. For instance, the silanol groups on amorphous silica can react with the organometallic precursor and therefore stabilize the single-site metal complex on silica surface ${ }^{16,17}$. Moreover, the electronic structure of the isolated metal centres can be modulated by varying the binding atoms between the metal and carbon support ${ }^{18,19}$. Though the crystalline solid carrier may be able to provide a well-defined coordination environment to accommodate a single metal atom, the location of the isolated atoms in a practical solid catalyst usually show a random distribution pattern due to the presence of heterogeneous surface defective $\operatorname{sites}^{20}$.

When the support is shifted to crystalline nanoporous (such as zeolites and MOFs), the homogeneity of the metal site can be improved if they are located in specific sites of the highly crystalline zeolites and MOFs, as illustrated in Figure 1. Moreover, the stability of the isolated atoms against sintering can be improved when being located within the pores or cavities of those materials, which is a critical issue for potential applications ${ }^{8,9}$.

The confinement effect has limited impact on the geometric structure of the isolated metal atoms, though different framework or extra-framework positions can influence their geometric configurations. Nevertheless, if the metal species are also coordinated to ligands, the confinement effect due to the Van der Waals interactions and dispersion forces between the zeolite framework and the metal complex will be more remarkable since the size of the metal complex may match with the void space in zeolites ${ }^{21}$. In 
that case, the geometric configuration of the metal complex can be influenced by the zeolite framework, which can further affect its reactivity and stereoselectivity ${ }^{22}$.

Taking the isolated metal atoms confined in zeolites as a simplified example, the electronic properties of the metal will depend on the coordination interaction with the framework oxygen atoms. It has been found that, during the activation treatment in helium flow, the coordination environment of $\mathrm{Cu}$ atom in CHA zeolite is dependent on the framework $\mathrm{Si} / \mathrm{Al}$ ratio $^{23,24}$. When the zeolite is switched from aluminosilicate to silicoaluminophosphate, the geometric configuration of the $\mathrm{Cu}$ species in CHA-type zeolites and the intermediates for $\mathrm{NH}_{3}-\mathrm{SCR}$ reaction will be different ${ }^{25,26}$.

Interestingly, isolated metal atoms or metal clusters within MOFs can show novel chemical states that are usually highly stable in the pure compound form. For instance, trivalent zirconium and hafnium can be stabilized in the nodes of $\mathrm{M}^{\mathrm{III}} \mathrm{H}-\mathrm{BTC}(\mathrm{M}=\mathrm{Zr}$, Hf; BTC $=1,3,5$-benzenetricarboxylate $)$ MOF structure $^{27}$. Theoretical calculations indicate that, the electronic properties of the isolated metal can be evaluated by density functional theory (DFT) calculations, which can be further used as reactivity descriptor ${ }^{28}$.

The rich chemistry offers great opportunities to extend the traditional coordination chemistry into solid state and may contribute to the discovery of metal sites with novel electronic structures. Isolated Pt atoms with metallic state can be stabilized in liquid polydimethylsiloxane-polyethene glycol ${ }^{29}$. If such structure could be mimicked in a MOF structure, low-valence metal centers would also be generated and they may show unique physiochemical properties.

\subsection{Metal clusters in confined space}

The profound influences of the support on the geometric and electronic structure of metal clusters have been shown in numerous systems, both in experimental and theoretical approaches ${ }^{30-32}$. Extrapolating that knowledge to metal clusters in confined materials, it can be expected that, the interaction between the metal clusters and porous environment, i.e. the confinement effect, will also impact the geometric and electronic structures of metal clusters. This effect is even more critical when the size of metal cluster matches the void space inside the porous structure. When a metal cluster containing a few atoms is encapsulated in MOFs or zeolites, depending on the interaction between the metal clusters and the support, the geometric structures of the metal clusters can either be stably anchored to the porous support or show some flexibility in the void space, especially under reaction conditions. Since the introduced metal clusters 
may match the size of the cavities or channels of MOFs or zeolites, their accessibility to the reactants and the mobility of metal clusters in the porous materials can be strongly influenced by the topological structure of the porous support ${ }^{33-35}$.

The electronic properties of metal clusters confined in carbon nanotubes are strongly related to the diameter of the carbon nanotubes and the location of metal clusters ${ }^{36,37}$. It can be expected that such confinement effect will also have impacts on the electronic structures of metal clusters confined in MOFs and zeolites. According to previous theoretical studies on the electronic structures of Au clusters, the contribution of the frontier orbitals in Au clusters consisting of a few atoms is higher than those in Au nanoparticles. Moreover, clusters with the same atomicity but different geometric structure show differences in the energy gap between HOMO and LUMO orbitals, as well as different geometric configuration $^{7,38}$. Following those results and considering the zeolite framework as an "infinite molecule" to interact with the metal cluster, when the geometry and size of the clusters matches with the size of the pores or channels, the geometrical and electronic interaction between the metal clusters and the framework will be optimized and specific configuration will be stabilized due to the overlap of the frontier orbitals between the metal clusters and zeolite framework ${ }^{39}$. For instance, electron donation from the Faujasite zeolite to the encapsulated Ir 4 clusters and its influence on Ir-Ir bonding has been observed by DFT calculations and detailed structural characterizations ${ }^{40}$. It can also be expected that, structural distortion can be induced when the metal-framework interaction is strong enough. Furthermore, the charge distribution in a single metal cluster will be determined by the conformation of the interface between the metal cluster and zeolite framework. Since the chemical composition of most zeolitic materials can be considered as inorganic metal oxides, subnanometric metal entities usually exhibit as positive charged species.

\subsection{Metal-ligand and metal-reactant interaction}

Following the concept established with traditional zeolite materials, the electronic properties of metal species can also be studied by probe molecules ${ }^{41}$. Though the size of a single atom is usually much smaller than the cavities or channels of zeolite structures, the confinement effect on the isolated atoms can be reflected on the geometric conformation of the reactant's transition state, which bonds to the single-atom species, leading to different reactivity compared to the reactions catalysed by metal atoms supported on open-structure carriers ${ }^{42,43}$. 
Taking the hydrogen affinity as a descriptor, influence of the electronic structure of the active sites on reactivity for $\mathrm{C}-\mathrm{H}$ activation has been studied by theoretical calculations ${ }^{44}$. When changing the support from graphene to MOF or zeolite, the hydrogenation affinity on transition metals (such as $\mathrm{Cu}, \mathrm{Fe}, \mathrm{Co}, \mathrm{Ni}$ etc) as well as the energy of the transition state of the single-atom species will change accordingly. Such effect can also be observed on single-atom Zn species confined in MOFs and zeolites. By changing the anchoring site for low-valent $\mathrm{Zn}$ ions $\left(\mathrm{Zn}^{+}\right)$stabilized in ZSM-5 and the organic linker of MOF-5, the electronic structures of $\mathrm{Zn}^{+}$can be modulated ${ }^{45}$. Unlike the case with ionic compensation between the isolated $\mathrm{Zn}^{+}$and ZSM-5, the MOF-5 structures with functionalized groups exhibit a delocalized charge distribution between the organic linker and the $\mathrm{Zn}^{+}$.

Regarding metal clusters confined in zeolites, the metal-reactant interaction can also be impacted by the coordination environment surrounding the metal clusters. The electronic structures of Pt clusters confined in NaY and H-USY zeolite was studied by X-ray absorption spectroscopy ${ }^{46}$. With stronger acidity (i.e. higher $\mathrm{Si} / \mathrm{Al}$ ratio or higher average electronegativity of the framework), charge transfer between Pt clusters and the bonding oxygen in the zeolite framework can occur, which further promotes the activity of Pt clusters for $\mathrm{H}_{2}$ activation. Such effect is also confirmed and even quantified by theoretical calculations on charge transfer between $\mathrm{Pt}_{6}$ cluster and isolated $\mathrm{Pt}$ atom and acid site in ZSM-5 framework $^{47,48}$. The electronic interaction will subsequently influence the adsorption and activation of reactants on the metal species ${ }^{49}$.

When discussing the subnanometric metal clusters confined in porous materials, their geometric and electronic structures are usually coupled together and will be further reflected on the metal-reactant interaction. For instance, the calculation results indicate that, the $\mathrm{Cu}-\mathrm{O}-\mathrm{Cu}$ angle will depend on the zeolite topology and the angle is smaller when confined in a small-pore zeolite ${ }^{50}$. Furthermore, the activation energy for $\mathrm{C}-\mathrm{H}$ bond cleavage on $\left[\mathrm{Cu}_{2}(\mu-\mathrm{O})\right]^{2+}$ cluster confined in small-pore zeolites (AEI, CHA and AFX) are lower than that confined in medium-pore zeolite (MFI). Besides, the transition state for C-H bond cleavage is stabilized on $\mathrm{Cu}-\mathrm{O}-\mathrm{Cu}$ sites with a smaller angle since the acceptor orbital energy of $\left[\mathrm{Cu}_{2}(\mu-\mathrm{O})\right]^{2+}$ is lower, which suggests the coupled nature of geometric and electronic structures for subnanometric species. In another work, a semi-quantitative study of the confinement effect of the zeolite framework was carried out with binuclear Fe sites in MFI zeolite for methane activation ${ }^{51}$. On one hand, the confinement effect can exert constrain to the binuclear Fe sites and limit their flexibility, which increase the barrier for $\mathrm{C}-\mathrm{H}$ activation. On the other hand, the intermediates formed during the cleavage 
of C-H bond can be stabilized inside the constrained environment, which lower the energy of the transition state globally.

When studying the interaction between the substrate molecule and the metal species confined in porous materials, the accessibility of the encapsulated metal species to the reactants should be considered. The molecular sieving effect will allow the diffusion of $\mathrm{CO}$ and $\mathrm{H}_{2}$ to Pt nanoclusters confined inside LTA zeolites while block larger ones like benzene ${ }^{52}$. Interestingly, if the LTA zeolite structure becomes partially amorphous as result of the exchange of $\mathrm{Na}^{+}$with $\mathrm{NH}_{4}^{+}$, only $\mathrm{H}_{2}$ can have access to the encapsulated Pt nanoclusters. It is proposed in those works that, the size-selection by the zeolite framework can be used for bifunctional catalysis which invokes hydrogen spillover from the encapsulated metal species to nearby acid sites ${ }^{53}$.

Nevertheless, the electronic interaction between the subnanometric metal species and the nanoporous materials is strongly related to how the composite materials are prepared. When the isolated atoms or metal clusters are incorporated through mild process, the binding interaction between the metal species and the porous materials are usually not very strong. In those cases, some coordination groups from the precursor may remain on the metal species, making those materials to be treated as immobilized metal complexes in a constrained environment. On the other hand, during the catalytic process, the intermediate consisting metal centre and the bonded reactants should also be considered as a whole complex, as illustrated in Box 1. The bonded ligands will impact together with the microporous framework on the structural features of the metal centres ${ }^{54}$.

Once the preparation involves high-temperature treatment, the coordination groups from the precursor are partially or completely removed and the metal atoms or clusters in as-prepared catalyst will be stabilized by the electron-donor atoms from the porous materials. Therefore, in a first approximation, the electronic interaction between metal species with more polarized zeolite framework will be stronger than that in MOFs, unless the MOF backbone is constructed by functional groups that can strongly interact with the metal species.

\section{Catalyst synthesis}

\subsection{Synthesis with Zeolites as support}

Several most frequently used synthesis methodologies for the generation of isolated metal atoms and 
clusters in zeolites are illustrated in Figure 2. By conventional impregnation or ion-exchange method, it is possible to introduce mononuclear metal complexes into zeolites ${ }^{55,56}$. However, by these two methods, part of the metal precursor may not be able to penetrate through the micropores and instead, become deposited on the surface or at sub-surface region ${ }^{57,58}$. As a consequence, those atomically dispersed metal species within the pores or cavities can migrate to surface and sinter into nanoparticles during thermal treatment or under reaction conditions. Therefore, in order to enhance the interaction between metal species and the zeolite framework, encapsulation of single-atom species into zeolite crystallites by onepot synthesis can be a more promising approach, which can be dated back to 1970s on the ship-in-bottle encapsulation of metal complexes in zeolite crystallites $^{59-61}$. Following that concept, more methods have been further developed for the encapsulation and stabilization of isolated atoms and metal clusters in zeolites. $^{62-68}$

The incorporation of subnanometric metal species can also be achieved by post-synthesis transformation of the zeolite structure. Taking a two-dimensional (2D) pure-silica MWW zeolite as precursor, subnanometric Pt clusters can be incorporated into the internal space between the layers of MWW zeolite and further stabilized by the 12 member-ring (12MR) supercages during the transformation of the $2 \mathrm{D}$ structure into $3 \mathrm{D}^{69}$. This strategy can also be extended to other metals and other layered zeolite materials, though the synthesis procedure may need to be optimized to achieve atomic dispersion ${ }^{70}$.

Reversible transformation between isolated atoms, subnanometric metal clusters and nanoparticles may occur under certain treatment conditions. For instance, Pt nanoparticles encapsulated in CHA zeolite can disintegrate into single Pt atoms during calcination in air and those isolated atoms can sinter into Pt nanoparticles again after reduction by $\mathrm{H}_{2}$. Taking advantage of the mobility of metal species in oxidative atmosphere at high temperature and the higher stability of Pt atoms confined inside zeolite crystallites, single Pt atoms can be generated in Al-containing CHA zeolite by trapping the Pt atoms from supported Pt catalysts on conventional supports like silica and alumina ${ }^{71}$. Interestingly, it has been found that, the driven force required for the dispersion of Pt particles into Pt isolated atoms is lower when Pt species are located inside zeolite, which probably can be ascribed to the confinement effect from the zeolite structure $^{72}$. As discussed before, the coordination environment of isolated atoms and clusters will be determined by their location in zeolite structure. To achieve that, a new strategy is developed to regioselectively generate single Pt atoms and Pt clusters in sinusoidal channels of pure-silica MFI zeolite ${ }^{73}$. 


\subsection{Synthesis with MOFs as support}

Similar to the methodologies discussed above for zeolites, the generation of isolated atoms and subnanometric metal clusters in MOFs can also be achieved by post-synthesis and one-pot synthesis approaches. In the presence of electron-donor functional groups in the organic linker of the MOF structure, single-atom species can be directly introduced by the coordination interaction between the organic linker and metal atoms ${ }^{74}$. Thanks to the flexibility of MOF structures, doped atoms can also be facilely introduced to the node position by post-synthesis method, such as ion-exchange or grafting ${ }^{75-77}$.

The metal species can also be introduced into MOF by atomic layer deposition inside the porous structure, using organometallic compounds as precursor ${ }^{78}$. Due to the relatively larger pore size, the incorporation of metal clusters into MOF structure can be more efficiently achieved by one-pot synthesis. $\mathrm{Pt}_{12}$ and $\mathrm{Au}_{25}$ clusters can be facilely encapsulated into MOF crystallites by one-pot synthesis ${ }^{79,80}$. In both works, Au clusters and Pt clusters are stabilized by thiol or CO, which can avoid the sintering of metal clusters into larger nanoparticles during the hydrothermal synthesis process. However, Au and Pt clusters are randomly distributed in the MOF crystallites without preferential location. If the organic linkers with stronger affinity to the metal clusters are employed in the synthesis, the more precise control on the location of those subnanometric metal clusters could be achieved.

Isolated atoms and metal clusters may also transform into each other after proper treatments. For instance, isolated $\mathrm{Pt}$ and $\mathrm{Pd}$ atoms can be introduced into MOF by ion-exchange treatment and those isolated atoms can form small clusters after mild reduction treatment. When the ion-exchange with MOF materials can be processed in a more controlled manner, the regioselective generation of subnanometric metal clusters in MOFs can also be achieved ${ }^{81,82}$.

Due to the lower stability of MOF, harsh conditions used in metal-zeolite materials for the redispersion of metal particles into isolated atoms or small clusters may not be applicable for metal-MOF materials. In such cases, the redispersion may require stronger oxidant or using liquid regents such as $\mathrm{CH}_{3} \mathrm{I}$ for redispersion of Au nanoparticles into $\mathrm{Au}$ atoms on solid carrier ${ }^{83}$.

\section{Characterization}

To confirm the presence of subnanometric metal species in the materials, multiple techniques should be employed to characterize the size, coordination environment and electronic structures of 
subnanometric metal entities confined in crystalline porous materials (see Table 1). In this section, several powerful techniques will be highlighted.

\subsection{Structural characterizations}

In the last two decades, the tremendous developments of aberration-correct scanning transmission electron microscopy (AC-STEM) and its wide application has made the direct visualization of isolated atoms or subnanometric metal clusters to be feasibly available in material science and catalysis community $^{84,85}$. The imaging on single metal atoms or subnanometric metal clusters on conventional solid carriers, such as metal oxides and carbon materials, can be readily achieved on the basis of different contrast between the metal entities and the support in the high-angle annular dark-field (HAADF) imaging mode ${ }^{86}$. However, for isolated atoms and small metal clusters supported on zeolites, the STEM measurement should be done under very low-dose conditions and the acquisition time should be short in order to preserve the zeolite structure ${ }^{87}$. Furthermore, ultramicrotomy treatment can be performed to visualize the metal species confined in the internal space of zeolite crystallites. Considering the complex structure of zeolites, isolated atoms or clusters can be anchored to the pore channels, cavities or cages in the crystallites. To reveal the location of metal entities confined in zeolites, a combined technique of high-resolution HAADF-STEM imaging and integrated differential phase contrast (iDPC) imaging has been recently developed to unveil the position of Pt atoms and clusters in MFI zeolite ${ }^{73}$. The position information of $\mathrm{Pt}$ is acquired by HAADF-STEM imaging while the crystal structure of MFI zeolite is resolved by iDPC imaging under low-dose conditions. This STEM-iDPC technique has also been used for identify the location of isolated Mo atom in ZSM- $5^{88}$.

The imaging on subnanometric metal entities confined in MOFs by STEM is even more challenging. In a recent work, isolated $\mathrm{Pt}$ atoms in aluminum-based porphyrinic MOF can be observed by highresolution STEM, though the structure of the Al-MOF is damaged ${ }^{89,90}$. To reduce the damaging effect from the beam, the measurement can be performed with a cryo-EM sample holder, which has been demonstrated to be effective for high-resolution imaging of MOF structures with atomic resolution ${ }^{91}$.

It is already known that, subnanometric metal species can exhibit dynamic structural evolution between isolated atoms and clusters under reaction conditions, which has been directly observed by in situ TEM ${ }^{72}$. Revealed by in situ STEM, Pt clusters can show amorphous structure and then transform into ordered geometric conformation at $350{ }^{\circ} \mathrm{C}$ in vaccum ${ }^{92}$. It can be expected that, direct observation 
of the structural evolution of single-atom catalysts under reaction conditions by in situ AC-STEM will bring more insights on their evolution behavior in the near future on the basis of the further developments of in situ sample holder and improvement of spatial resolution.

Tomography based on AC-STEM imaging can achieve the reconstruction of the 3D structural information of metal nanoparticles ${ }^{93}$. Considering the necessity of acquisition of multiple images at different orientation for 3D reconstruction, the tomography work on zeolites and MOFs will be quite difficult, since it requires better protection of materials under the electron beam and advanced algorithm for 3D reconstruction with a small number of projections.

The position of the isolated atoms or metal clusters can also be determined by X-ray crystallography ${ }^{81,94}$. Compared to TEM-based techniques, the X-ray crystallography can provide structural information with very high accuracy and the damage to the sample is much less than that by TEM. However, the X-ray crystallography requires highly crystalline and highly uniform samples, which demands a very high loading of metals in the MOF structures.

Not only the size and location, but the chemical compositions of the subnanometric metal species confined in crystalline porous materials are also key structural information. Isolated atoms can be detected by electron energy loss spectroscopy and X-ray energy dispersive spectroscopy ${ }^{95,96}$. However, more powerful detector and extremely high sample stability is required to obtain reliable information by such analysis ${ }^{97}$. On the other hand, to obtain the chemical composition information in $3 \mathrm{D}$, atom probe tomography (APT), which has been widely used for nanoscale and bulk materials, can be a very useful tool to depict the chemical composition of porous composition materials with atomic resolution $^{98,99}$. For instance, the $3 \mathrm{D}$ distributions of $\mathrm{Al}$ and $\mathrm{Cu}$ in zeolite crystallites and $\mathrm{Ni}$ atoms embedded in carbon matrix have been revealed by APT with a spatial resolution below $1 \mathrm{~nm}^{100-102}$. However, the sample preparation for the APT measurement and data analysis is not as straight forward as AC-STEM, which limits its wide application in catalysis ${ }^{103}$.

\subsection{Spectroscopy Characterizations}

To gain global information on the chemical states and coordination environment of subnanometric metal species, X-ray absorption spectroscopy is a widely used and complementary tool to AC-STEM. According to the results obtained from X-ray near edge absorption structure (XANES) and extended X-ray absorption fine structure (EXAFS), one can determine the chemical states and neighboring 
atoms of a metal center ${ }^{104}$. By correlating the spectroscopic information from EXAFS and images from AC-STEM, one can determine the size and plausible structures of the metal species ${ }^{73,105}$. However, it should be noted that, subnanometric metal species are more sensitive than the conventional metal nanoparticles to the environmental changes and the experimental conditions used in many of the XAS measurements done in the literature were different to the synthesis or reaction conditions, which may not be able to show the real structures of the working catalytic sites ${ }^{8}$. Therefore, EXAFS measurements are always encouraged to be performed under reaction conditions. The application of time-resolved scanning extended X-ray absorption fine structure under in situ or operando conditions will play a key role for understanding how the coordination environment of subnanometric metal species evolves under reaction conditions ${ }^{106,107}$.

The interpretation of XANES and EXAFS spectra to address the coordination structure of isolated metal species or bimetallic metal clusters at atomic level is always challenging for solid catalysts due to the heterogeneity of the material and the dynamic structural transformation under different conditions. With the assistance from supervised machine learning, the identification of the plausible metal species in the solid catalyst based on the subtle variations in the experimental data can be achieved ${ }^{108}$. By combining the theoretical modelling and the experimental spectra, it is possible to clarify the contribution of different types of metal species in a single catalyst or the plausible structure of bimetallic metal clusters ${ }^{109,110}$.

X-ray photoelectron spectroscopy (XPS) may also be not applicable in most of the cases because the encapsulated metal species in porous matrix cannot be reached by X-ray, unless the metal atoms or clusters are embedded in thin porous structure $(<10 \mathrm{~nm})$. Electronic spectroscopy (including UVvis absorption spectroscopy and fluorescence spectroscopy) are very useful tool to measure the electronic properties of metal atoms and clusters confined in zeolites. Especially, the fluorescence emission properties are quite sensitive to the electronic structures of metal atoms and clusters, as demonstrated with $\mathrm{Cu}$ - and Ag-zeolites ${ }^{111-113}$. Besides, by in situ infrared (IR) spectroscopy using CO or other probe molecules, the electronic structures of the metal entities will be reflected in the IR bands $^{114,115}$. The fingerprints of $\mathrm{CO}$ adsorption bands can be a facile and efficient tool to test the heterogeneity of the synthesized metal catalysts ${ }^{116}$. As a powerful tool for solid materials, solid-state nuclear magnetic resonance (ssNMR) can be directly used to study the structures of the porous matrix (such as the defects in zeolites or the linkers in MOFs) or to investigate the coordination environment 
of the metal species by using probe molecules such as trimethylphosphine oxide ${ }^{117-119}$.

\subsection{Combination of different techniques}

Each characterization has its advantage and limitation, as summarized in Table 1. For instance, subnanometric metal clusters could be oxidized by air. Therefore, when the EXAFS spectra of metalzeolite material are recorded directly without proper activation treatments, spectra with features of isolated metal atoms may be obtained, though a large number of metal clusters are observed by AC-STEM ${ }^{8,120}$. On other hand, due to the low contrast of isolated atoms, only part of them could be observed by ACSTEM. Therefore, EXAFS and IR spectroscopy can be complementary for the gain of global information on the metal dispersion. It is critical to perform characterizations on both the structure of porous matrix with metal species and the metal-reactant interaction for understanding the catalysis of confined metal species $^{121}$.

\section{Catalysis of confined catalysts}

In this section, the catalytic properties of subnanometric metal entities confined in zeolites and MOFs for a variety of heterogeneous catalytic reactions will be discussed. It should be mentioned that, the metal-zeolite materials to be discussed in this section will be mainly focused on extra-framework metal species confined in zeolite structures since the reactivities of framework-type metal-zeolite materials have already been covered in previous reviews ${ }^{122}$. While subnanometric metal entities bonded to both the nodes and linkers in MOF structures will be discussed. Limited by the space, we will focus on reactions that can provide important fundamental insights or they are of broad interest for practical applications.

\subsection{Water-gas shift reaction}

Water-gas shift (WGS) reaction is an important industrial process to produce hydrogen ${ }^{123}$. Taking advantage of alkali ions ( $\mathrm{Na}$ or $\mathrm{K}$ ) as promoter, isolated $\mathrm{Au}$ and $\mathrm{Pt}$ atoms can be stabilized in zeolites and show high reactivity for low-temperature WGS reaction ${ }^{124,125}$. Regardless of the support for single $\mathrm{Au}$ and Pt atoms, the apparent activation energy for WGS reaction in various catalysts are nearly the same, indicating a common nature of the active sites. 
The unique role of isolated atoms for water-gas shift reaction has also been shown in MOF materials. Positively charged $\mathrm{Pt}^{1+}$ atoms have been introduced and stabilized in the channels of a MOF by a postsynthesis approach ${ }^{90}$. Single-crystal X-ray diffraction reveals that, each $\mathrm{Pt}^{1+}$ atoms are coordinated with four water molecules, with charge balance from the MOF framework. Interestingly, this singleatom Pt-MOF material show much higher activity for low-temperature WGS reaction than conventional Pt supported on zeolites or carbon. The working temperature of the isolated Pt atoms confined in MOF is also lower than the state-of-art Pt atoms stabilized by alkaline metals on metal oxides $^{125}$. Isotopic studies and theoretical calculations show that, the water molecules surrounding the $\mathrm{Pt}^{1+}$ atoms can continuously react with $\mathrm{CO}$ and then be regenerated by external water, making both oxygen atoms in the $\mathrm{CO}_{2}$ product coming from the water molecules.

Again, as mentioned before, the stability of single-atom species under water-gas shift reaction conditions should be carefully examined. Indeed, a potential agglomeration behavior of Pt and $\mathrm{Au}$ atoms has been reported ${ }^{72,126}$. It can be expected that, even the isolated atoms may sinter during WGS reaction, the porous matrix can constrain the resultant agglomerates below $1 \mathrm{~nm}$, as stabilized metal clusters in zeolites or MOFs.

\subsection{Methane activation}

The selective transformation of methane into fuels and chemicals has always been one of the Holy Grails in chemistry and its importance is increasing nowadays due to the emerging demands on clean energy $^{127}$. The non-oxidative conversion of methane into ethene and aromatics is a highly desired single-step reaction due to the economic consideration and feasibility for industrial adoption ${ }^{128}$. In 1990s, it was reported that methane can be converted into aromatics by Mo-zeolite materials ${ }^{129}$. An induction period for the production of benzene is observed with the as-prepared Mo-zeolite (such as Mo/ZSM-5 and Mo/MCM-22), which can be associated to the transformation of atomically dispersed Mo species into subnanometric $\mathrm{Mo}_{\mathrm{x}} \mathrm{C}_{\mathrm{y}}$ clusters ${ }^{130,131}$. The in situ formed MoxCy clusters initiate the breaking of $\mathrm{C}-\mathrm{H}$ bond in the methane molecules, leading to the formation of ethene through $\mathrm{C}-\mathrm{C}$ coupling. In the presence of acid sites in the zeolite framework, ethene molecules are subsequently oligomerized and aromatized into benzene. Therefore, medium-pore zeolites with 10MR structure are the most common support for Mo in this reaction since the pore size perfectly match the aromatic ring. A combined experimental and theoretical study show that, the synergy between the binuclear 
$\left[\mathrm{Mo}_{2} \mathrm{C}_{2}\right]^{2+}$ species and the aromatic pool confined in the zeolite is a key factor for the conversion of methane into aromatics ${ }^{132}$. This work introduces a new hypothesis that subnanometric metal species may work together with the intermediates formed inside the microporous environment.

Despite the tremendous efforts on identification of the active sites and improving the catalytic performance, the fast coke deposition on Mo-zeolite catalysts hinders this process for industrial application ${ }^{133,134}$. Recently, the utilization of an ion-conduct membrane reactor has been reported, in where the $\mathrm{H}_{2}$ can be extracted from the reaction mixture to shift the thermodynamic equilibrium and the coke can be removed by the oxygen ions transported through the $\mathrm{BaZrO}_{3}$-based membrane ${ }^{135}$.

From a thermodynamic point of view, the introduction of $\mathrm{O}_{2}$ can reduce the energy barrier for the activation of C-H bond in methane. Indeed, the partial oxidation of methane to syngas can be achieved by $\mathrm{Rh}$ clusters confined in zeolites ${ }^{136}$. Those $\mathrm{Rh}$ clusters stabilized in MOR zeolite are more active than Rh particles support on open-structure solid carriers at low working temperature $\left(450{ }^{\circ} \mathrm{C}\right)$. As an indirect route for methane conversion, the partial oxidation of methane to syngas still requires high temperature to achieve high yield of $\mathrm{CO}$ and $\mathrm{H}_{2}$.

To avoid the over-oxidation of methane and directly produce methanol, a chemical looping strategy is developed based on Cu-zeolites with inspiration from the monooxygenase enzyme in nature, which containing binuclear $\mathrm{Cu}$ active centers ${ }^{137}$. In that process, $\mathrm{Cu}$-zeolite is oxidized in air at high temperature (usually $>400{ }^{\circ} \mathrm{C}$ ) and then cooled down to react with methane to form surface-bound methoxy species and methanol. After a desorption treatment in the presence of water steam, methanol can be produced and the $\mathrm{Cu}$-zeolite will be regenerated by high-temperature calcination in air ${ }^{138}$. The oxidant in the chemical looping process can also be replaced by water instead of $\mathrm{O}_{2}{ }^{139}$. Furthermore, the oxidation of methane to methanol can also be achieved under continuous flow conditions, though the methane conversion is very low ${ }^{140}$. Kinetic and spectroscopic studies show that, the isolated $\mathrm{Cu}$ atoms confined in zeolites could be mobile under the continuous reaction conditions and may migrate to form $\mathrm{Cu}-\mathrm{O}-\mathrm{Cu}$ dimer species, which is the working active sites for methane conversion to methanol $^{141}$.

Beside $\mathrm{Cu}$-zeolites, $\mathrm{Cu}-\mathrm{MOF}$ materials have also been used for this application and shown promising performance for production of methanol ${ }^{142}$. Since the chemical looping process requires high-temperature calcination in air, NU-1000, a Zr-MOF with high thermal stability, has been chosen 
as the support for subnanometric $\mathrm{Cu}$ species. $\mathrm{Cu}_{3} \mathrm{Ox}$ clusters with linear conformation were generated in NU-1000 and methanol was produced with a moderate yield and selectivity ${ }^{143}$.

Most of the works for methane oxidation to methanol are related to subnanometric $\mathrm{Cu}$ species confined in zeolites or MOFs, though the atomicity of $\mathrm{Cu}$ clusters could be two or three ${ }^{144}$. Notably, it has been reported that mononuclear $\mathrm{Cu}$ species supported on alumina and silica can also be active for selective oxidation of methane to methanol ${ }^{145,146}$, as observed in particulate methane monooxygenase ${ }^{147}$. It has been found that, $\mathrm{Cu}$ dimers show significantly higher methanol yield than the isolated $\mathrm{Cu}$ atoms and $\mathrm{Cu}_{3}$ clusters, though the selectivity to methanol is close in the all cases and the materials are not highly uniform. These results indicate the importance of controlling the atomicity of metal species to establish the relationship between metal atomicity and reactivity ${ }^{143}$.

By incorporating Rh species into ZSM-5 zeolite to form heterogeneous single-site Rh catalysts, the oxidative coupling between methane and $\mathrm{CO}$ by $\mathrm{O}_{2}$ to form acetic acid can be achieved under mild conditions $^{148}$. When $\mathrm{Rh}$ atoms are supported on conventional supports such as $\mathrm{TiO}_{2}$, only methanol is obtained, suggesting the necessity of using zeolite as the support for Rh atoms. Isotopic studies indicate that the reaction pathway on heterogeneous $\mathrm{Rh}$ catalyst is similar to that in homogeneous system, which involves the direct $\mathrm{C}-\mathrm{H}$ activation of $\mathrm{CH}_{4}$ by $\mathrm{Rh}$ and $\mathrm{C}-\mathrm{C}$ coupling between $\mathrm{CO}$ and $-\mathrm{CH}_{3}{ }^{149}$. In this example, the synergistic role of isolated $\mathrm{Rh}$ atoms and the acid sites in the zeolite framework enable the above transformation, highlighting the unique reactivity of confined metal species in microporous materials.

\subsection{Dehydrogenation of alkanes}

With the boom in production of shale gas, dehydrogenation of light alkanes to corresponding olefins is of great interest to chemical industry in recent years ${ }^{150,151}$. Thermodynamically, the dehydrogenation of light alkanes requires high reaction temperature, which limits the application of MOFs for this application and makes zeolites as suitable materials for dehydrogenation of alkanes.

It has been shown that subnanometric Pt species stabilized in MCM-22 zeolite are more active than Pt nanoparticles for dehydrogenation of propane to propylene at $550{ }^{\circ} \mathrm{C}^{69}$. It should be noted that, though the subnanometric Pt species are mainly confined between the layers of MCM-22 zeolite, the location of Pt atoms and clusters are not precisely controlled. By one-pot synthesis, Pt clusters of $\sim 0.5$ $\mathrm{nm}$ can be regioselectively generated in the 10MR sinusoidal channels of MFI zeolite and their 
electronic properties can be further modulated by the introduction of subnanometric Sn species ${ }^{73}$. Those subnanometric Pt clusters with uniform size and location in MFI zeolite show high activity for propane dehydrogenation to propylene as well as high stability against sintering (see Figure 3 ).

Due to the reductive atmosphere under the reaction conditions for dehydrogenation of alkanes, isolated metal atoms will agglomerate into subnanometric Pt clusters or even small nanoparticles. Pt isolated atoms stabilized in Y zeolite can partially transform into Pt clusters and nanoparticles after ethane dehydrogenation reaction at $700{ }^{\circ} \mathrm{C}^{67}$. Considering the higher stability of isolated atoms in oxidative atmosphere, isolated metal atoms confined in microporous materials may be more suitable for oxidative dehydrogenation of alkanes to olefins. A single-atom Co-MOF has been reported for oxidative dehydrogenation of propane to propylene at $\sim 200{ }^{\circ} \mathrm{C}^{152}$.

It has been well established that, subnanometric Pt clusters confined in the 12MR channels of KLTL zeolite are the active sites for dehydrocyclization of alkanes (C6-C8) to aromatics ${ }^{153,154}$. The $\mathrm{Pt} /$ KLTL catalyst with Pt clusters of $0.6-0.7 \mathrm{~nm}$ shows higher selectivity to aromatics and lower deactivation rate for conversion of $n$-heptane to benzene and toluene ${ }^{155}$.

\subsection{Hydrogenation reactions}

As a simple test reaction, the hydrogenation of light olefins has been used to study the structurereactivity behavior of subnanometric metal species confined in porous materials. The reaction rate for ethene hydrogenation can be correlated with the IR bands of CO adsorbed on single Ir atoms supported on various porous carriers ${ }^{156}$. These results imply that, the metal-support electronic interaction can influence the reactivity for hydrogenation reactions, as also demonstrated by tuning the organic linkers in MOF-supported Ni catalyst ${ }^{157}$. Due to the molecular sieving effect of the zeolite framework, when metal nanoclusters are confined in zeolites, shape-selective catalysis can be achieved with metalzeolite materials $^{66,68}$. For instance, high activity for ethene hydrogenation can be achieved with Pt@CHA material comprising Pt nanoclusters while propylene is barely hydrogenated due to the diffusion problem. Furthermore, the molecular sieving effect can also protect the confined metal clusters from being poisoned by organic molecules, such as thiophenol ${ }^{62}$.

When a hydrogenation reaction comprises several elementary steps to various products, the control of the hydrogenation to the desired product will be a challenge. Single-site Ni(II) hydride species confined in a Ti-MOF have been reported for the hydrogenolysis of model lignocellulose 
compounds ${ }^{158}$. In the case of benzyl phenyl ether, only toluene and cyclohexanol can be obtained under mild conditions $\left(140{ }^{\circ} \mathrm{C}, 1\right.$ bar of $\left.\mathrm{H}_{2}\right)$. Conventional supported $\mathrm{Ni}$ nanoparticles on amorphous silica will give mixed products of toluene, phenol and cyclohexanol ${ }^{159}$.

The reactivity of isolated metal atoms confined in MOFs needs further improvement. For instance, single-site Co atoms confined in MOFs do not show clear advantage on the catalytic performance when comparing to isolated Co atoms in $\mathrm{N}$-doped carbon or even Co nanoparticles covered by carbon layers for the hydrogenation of nitroarenes ${ }^{160-164}$. In the scope for hydrogenation of unsaturated compounds (e.g. nitroarenes, ketones), the yields of some products are obviously lower than those obtained with nanoparticulate Co catalysts, which could be caused by the low activity of isolated Co sites for $\mathrm{H}_{2}$ activation. In a comparative study, $\mathrm{Ru}_{3}$ clusters show much higher activity than isolated $\mathrm{Ru}$ atoms when both are confined in zeolitic imidazolate framework (ZIF-8) ${ }^{165}$.

The hydrogenation of $\mathrm{CO}_{2}$ into hydrocarbons or oxygenates has been intensively studied in recent years due to the concerns on the influence of $\mathrm{CO}_{2}$ on global warming. Conventionally, nanoparticulate catalysts, including both noble metals and non-noble metals, are used as the catalysts for $\mathrm{CO}_{2}$ hydrogenation reaction. In a recent work, two cooperative $\mathrm{Cu}(\mathrm{I})$ atoms anchored on the $\mathrm{Zr}_{12}$ node of a Zr-MOF material can selectively convert $\mathrm{CO}_{2}$ into ethanol through the $\mathrm{C}-\mathrm{C}$ coupling between a formyl intermediate and methanol ${ }^{166}$. Under the same reaction conditions, the conventional $\mathrm{Cu} / \mathrm{ZrO}_{2}$ or $\mathrm{Cu}$ nanoparticles confined in the same MOF structure mainly produced methanol and only gave a selectivity of $\sim 10 \%$ to ethanol. The high selectivity for hydrogenation of $\mathrm{CO}_{2}$ to methanol on $\mathrm{Cu}$ nanoparticles can be associated to the fast desorption of methanol or the low C-C coupling reactivity between the $\mathrm{C} 1$ intermediates on the continuous metallic $\mathrm{Cu}$ surface. The unique reactivity of metal atoms confined in MOF structures has also been demonstrated with metallic $\mathrm{Pt}_{2}$ clusters within a thioether-functionalized $\mathrm{MOF}^{82}$. The Pt-MOF material are found to be active for the production of $\mathrm{NH}_{4} \mathrm{CN}$ from $\mathrm{CO}$ and $\mathrm{NH}_{3}$ at room temperature while the commonly used $\mathrm{Pt}$ compounds or $\mathrm{Pt}$ supported on carbon or zeolites are inactive under the same conditions. The unique activity could be ascribed to the strong adsorption of $\mathrm{NH}_{3}$ by the MOF framework and the favorable $\mathrm{C}-\mathrm{N}$ coupling reaction to form amide intermediate on $\mathrm{Pt}_{2}$ cluster.

The shape-selectivity resulting from the confinement effect allows to modulate the hydrogenation and hydroisomerization reactions by tuning the spatial distribution of metal species in the microporous matrix. For instance, $\mathrm{H}_{2}$ can diffuse to metal clusters trapped in small-pore zeolites and the activated 
$\mathrm{H}$ species then migrate to the external surface for subsequent reactions ${ }^{167}$. In the case of hydroisomerization reactions, the product distributions can be modulated by tuning the spatial distribution of the metal particles and acid sites in the porous matrix ${ }^{168}$.

\subsection{Oxidation reaction}

Since the first report in 1998, the epoxidation of propylene to propane oxide with mixture of $\mathrm{H}_{2}$ and $\mathrm{O}_{2}$ using Au-Ti bifunctional catalysts has attracted great attention ${ }^{169}$. Later studies on this reaction suggest that, Au/TS-1 zeolite is one of the most efficient systems ${ }^{170}$. Theoretical and experiments studies show that, subnanometric Au clusters located inside the TS-1 zeolite are much more active than the larger Au nanoparticles on the external surface ${ }^{171,172}$. Au clusters are responsible for the generation of $\mathrm{H}_{2} \mathrm{O}_{2}$ from $\mathrm{H}_{2}$ and $\mathrm{O}_{2}$ while the isolated Ti sites in TS-1 zeolite serve as the acid catalysts for epoxidation of propylene, demonstrating the synergistic effect between the confined metal species and the porous materials.

The unique reactivity of subnanometric Au clusters can be reflected in the aerobic oxidation of cyclohexane to cyclohexanol and cyclohexanone ${ }^{173}$. The reaction between cyclohexane and $\mathrm{O}_{2}$ to produce radical species is more efficient on Au clusters than that on Au nanoparticles, resulting in a shorter induction period. When Au clusters are confined in MCM-22 zeolite, they are protected from leaching to the liquid and sintering into nanoparticles under reaction conditions.

The confinement effect from the porous framework can also be reflected in direct oxidation of benzene to phenol. In 2006, the direct oxidation of benzene to phenol using $\mathrm{O}_{2}$ as oxidant with Re/ZSM-5 catalyst in the presence of $\mathrm{NH}_{3}$ was reported ${ }^{174}$. Systematic in situ structural characterizations indicate that, N-modified Re clusters confined in the 10MR channels could be the active sites ${ }^{175}$. If other zeolites such as Beta, USY or Mordenite (with 12MR pore structures) was used as the zeolite support, much lower activity and selectivity was obtained, indicating the critical role of confinement effect from the zeolite structure.

\subsection{DeNOx reactions}

It is well known that $\mathrm{Cu}$-exchanged small-pore zeolites are excellent catalysts for selective catalytic reduction $(\mathrm{SCR})$ of nitrogen oxides $(\mathrm{NOx})$ with ammonia $\left(\mathrm{NH}_{3}\right)^{176}$. deNOx reactions on Cu catalyst is a structure-sensitive reaction, in which $\mathrm{NH}_{3}$ primarily react with $\mathrm{O}_{2}$ to produce $\mathrm{NOx}$ on $\mathrm{CuOx}$ 
nanoparticles while $\mathrm{NH}_{3}$ will react with $\mathrm{NO}$ to form $\mathrm{N}_{2}$ on atomically dispersed $\mathrm{Cu}$ species ${ }^{177}$. Moreover, $\mathrm{Cu}$ species can migrate in the zeolite crystallites under catalyst activation and $\mathrm{NH}_{3}-\mathrm{SCR}$ reaction conditions ${ }^{178}$. In a systematic study on the influence of $\mathrm{Cu}$ density in the $\mathrm{CHA}$ zeolites on their $\mathrm{NH}_{3}$-SCR reactivity, the dynamic structure of $\mathrm{Cu}$ species confined in CHA zeolite is revealed (see Figure 7$)^{179}$. They have proposed a reaction mechanism that single-site $\mathrm{Cu}$ species can travel through the 8MR window of the CHA supercages and form binuclear $\mathrm{Cu}$ species as the active sites for lowtemperature $\mathrm{NH}_{3}-\mathrm{SCR}$ reaction (see Figure 7D). The importance of formation binuclear $\mathrm{Cu}$ species can explain the low $\mathrm{NH}_{3}$-SCR activity for $\mathrm{Cu}$-zeolite materials with low $\mathrm{Cu}$ density since the possibility to form such $\mathrm{Cu}$ pairs is much lower in those samples containing highly diluted single-site $\mathrm{Cu}$ species $^{180}$. In that respect, to maximum the dispersion of $\mathrm{Cu}$ atoms in zeolites, more efficient synthesis methodologies have been developed to encapsulate high-loading $\mathrm{Cu}$ species in zeolites ${ }^{181}$. In a similar manner, zeolites can also serve as the host for atomically dispersed Pd atoms for generation of passive NOx adsorbers for low-temperature control of emissions from diesel engines ${ }^{182,183}$.

Noted that, the Brønsted acid sites can participate the $\mathrm{NH}_{3}-\mathrm{SCR}$ reaction by interacting with $\mathrm{NH}_{3}{ }^{184}$. The advantage of $\mathrm{Cu}$-zeolite materials over $\mathrm{Cu}$ supported on conventional solid carriers can be related to the synergistic effect of acid sites in the zeolite framework and subnanometric $\mathrm{Cu}$ species confined in the cavities. Control of the spatial distribution of $\mathrm{Cu}$ and $\mathrm{Al}$ species is also a key issue on preparation of highly stable $\mathrm{Cu}$-zeolite materials for $\mathrm{NH}_{3}-\mathrm{SCR}$ reaction ${ }^{185}$.

Nevertheless, it is found that the confinement environment inside the zeolite crystallites can accelerate NO oxidation reaction inside pure-silica zeolites ${ }^{186}$. By combining the size and confinement effect, the catalytic NO reduction with $\mathrm{CO}$ is achieved by subnanometric Pt clusters confined in MCM22 zeolite at 140-200 K while isolated Pt atoms are not stable under such conditions and agglomerate into Pt clusters ${ }^{187}$. The unique electronic structures of confined Pt clusters in MCM-22 are proposed to account for the $\mathrm{NO}$ dissociation at low temperature and further $\mathrm{CO}$ oxidation to $\mathrm{CO}_{2}$ as well as the recombination of $\mathrm{N}$ species to $\mathrm{N}_{2}$.

To our best knowledge, though there is no report on catalytic deNOx reactions based on $\mathrm{Cu}-\mathrm{MOF}$ materials, the application of $\mathrm{Cu}-\mathrm{MOF}$ or other MOF materials for adsorption of NOx has already been demonstrated $^{188}$. Since MOF can be efficient absorbent for harmful gases, the introduction of functional metal components into the porous structures of MOF may introduce synergistic effects ${ }^{189}$. 
In principle, $\mathrm{Cu}-\mathrm{MOF}$ materials with suitable stability should be potential materials for catalytic removal of NOx.

\subsection{Organic reactions}

As the increasing ethene supply from steam cracking of ethane and the decreasing olefin products from fluid catalytic cracking, the on-purpose production of propylene and higher olefins has been intensively investigated and developed ${ }^{190}$. Basically, the transformation of ethene into higher olefins involves the ethene oligomerization and olefin metathesis reaction, both of which can be catalyzed by single-site metal species confined in porous materials. In 2003, Ni-H-Beta catalyst was reported for heterogeneous oligomerization of ethene under industrial relevant conditions ${ }^{191}$. The large-pore structure of nanocrystalline Beta zeolite and its lack of cages enhance the mass transportation and avoid the blockage of active $\mathrm{Ni}$ sites due to the formation of bulky oligomers. the $\mathrm{Ni}^{2+}$ stabilized by the Beta zeolite can firstly interact with ethene to form a nickel ethenyl hydride intermediate, which subsequently initiate the oligomerization reaction through the classical Cossee-Arlman mechanism ${ }^{192}$.

Recently, Dincă et al. have reported the application of Ni-substituted Zn-MOF (Ni-MFU-4l) as highly selectivity ( $\sim 96 \%$ selectivity to 1-butene) catalyst for dimerization of ethene in batch reactor via a Cossee-Arlman mechanism with high activity and selectivity to 1-butene (see Figure 8) ${ }^{193,194}$. Nevertheless, single-site Ni species can also be generated in covalent-organic framework (COF) through the bonding between $\mathrm{Ni}$ cations and N-containing ligands in the $\mathrm{COF}^{195,196}$. The Ni-COF catalysts showed comparable activity to those classic homogeneous counterparts and a much higher selectivity to C6+ olefins (>40\%). By comparing the Ni catalysts confined in zeolites and MOFs, it appears that higher selectivity to 1-butene can be achieved with Ni confined in organic framework, though both cases follow the same mechanism ${ }^{197}$. However, taking into account the regeneration of the deactivated Ni catalyst, the highly stable Ni-zeolite materials seem to be more practical.

The activation of carbine by transition metals into metal carbenoids is a powerful and broadly used strategy for organic synthesis. $\mathrm{Pd}_{4}$ clusters stabilized in the MOF channels show remarkable activity for the Buchner reaction of benzene, while homogeneous Pd compounds or Pd supported on conventional solid carriers and zeolites show very low or even zero activity ${ }^{81}$. The unique reactivity of confined $\mathrm{Pd}_{4}$ clusters can be ascribed to its metastable mixed-valence $0 /+1$ oxidation state. Another application of Pd clusters (with different atomicity) confined in MOF have been reported for catalysing 
the homocoupling of thienylboronic acids and terminal alkynes ${ }^{198}$.

Single-site chiral metal catalysts confined in mesoporous silica and carbon nanotubes have been reported for asymmetric catalysis and the enantioselectivity is related to the morphology of the solid carrier $^{199,200}$. Indeed, MOFs with chiral features have also been shown to be effective heterogeneous catalyst for acid-base catalysis and redox catalysis ${ }^{201}$. Asymmetric sequential alkene epoxidation and subsequent epoxide ring-opening reactions can be performed with the cooperative metal sites bonded to different linkers ${ }^{202}$. It can be expected that, by tuning the morphology of the MOF structure, the scope for those organic reactions can be further extended by increasing the accessibility of reactants to the chiral active sites ${ }^{203}$.

By incorporating isolated metal species in MOFs, the stability and recyclability can be greatly improved without much compromise in reactivity. For instance, after functionalization treatment of the IRMOF-3 structure to form Schiff base ligand, Au atoms can be stabilized by the organic linker and used for the coupling of N-protected ethynylaniline, amine, and aldehyde ${ }^{204}$. Isolated $\mathrm{Au}(\mathrm{III})$ species can be stabilized within MOFs consisting of rigid structure as recyclable catalysts for 1,5-enyne cycloisomerization and alkynyl cycloheptatriene cycloisomerization reaction, in where the unimolecular decomposition pathway of the well-defined $\mathrm{Au}(\mathrm{III})$ species is precluded ${ }^{205}$. By incorporating isolated $\mathrm{Cu}$ species in the node positions of ZIF-8, a recyclable $\mathrm{Cu}$ catalyst can be prepared for [3 + 2] cycloadditionof azides with alkynes and condensation reactions ${ }^{206}$.

\subsection{Photocatalysis and Electrocatalysis}

As insulator, the negligible electrical conductivity limits the application of metal-zeolite materials for photocatalysis and electrocatalysis. Therefore, we will focus on discussing the application of metalMOF materials containing isolated atoms and clusters in photocatalytic and electrocatalytic reactions ${ }^{207,208}$. Though zeolite cannot be the light absorbent for visible light, it has been shown in some works that, small molecules such as methane can be activated by zeolites under short-wavelength UV light ${ }^{209}$. The non-oxidative coupling of methane to ethane can be catalyzed by Zn-zeolite material under UV light ${ }^{210}$. Mechanistic studies show that, $\mathrm{Zn}^{2+}$ can be reduced to $\mathrm{Zn}^{+}$under UV light irradiation and methane can be activated on $\mathrm{Zn}^{+}$sites under the excitation by light. The $\mathrm{C}-\mathrm{H}$ bond in the activated methane molecule further react with another methane molecule for the formation of $\mathrm{C}-\mathrm{C}$ bond. 
One typical purpose for the introduction of metal atoms or clusters in MOFs is to be utilized as cocatalyst in photocatalytic process. For instance, Pt isolated atoms can be incorporated into the organic linkers of an Al-MOF as the co-catalysts for photocatalytic $\mathrm{H}_{2}$ evolution ${ }^{89}$. In another work, by controlling the morphology of the MOF crystallite, a Pt-MOF layered material with high-loading isolated $\mathrm{Pt}$ atoms exhibits remarkable activity for photocatalytic $\mathrm{H}_{2}$ evolution reaction ${ }^{211}$. Besides, MOF-based catalysts can also be applied for photocatalytic $\mathrm{CO}_{2}$ reduction by using isolated metal species reducing $\mathrm{CO}_{2}$ with photo-generated electrons from the MOF matrix or other photosensitizer ${ }^{212-214}$.

When the MOF structure is constructed based on $\pi$-conjugated system, the high electric conductivity enables it to be potential candidate material for electrocatalysis ${ }^{215}$. In 2016, Ni-MOF materials were reported for electrocatalytic oxygen reduction reaction and shown excellent performance compared to other electrocatalysts based on non-noble metals ${ }^{216}$. To further enhance the conductivity, the MOF structure consisting single-site metal species can be supported on a conductive support to form a heterojunction structure. By assembling benzene-1,2,4,5-tetracarbonitrile with $\mathrm{Fe}$ atoms into a $\pi$ conjugated planar system supported on grapheme, the composite material can achieve comparable power density and cycling stability as commercial Pt/C catalyst in the Zn-air battery ${ }^{217}$.

The application for electrocatalytic $\mathrm{CO}_{2}$ reduction by metal-MOF materials has also been explored. With a cobalt-porphyrin MOF, the electrocatalytic reduction of $\mathrm{CO}_{2}$ to $\mathrm{CO}$ can be achieved with a selectivity of $76 \%$ and a TON of 1400 per Co site ${ }^{218}$. Spectroelectrochemical measurements show that $\mathrm{Co}(\mathrm{II})$ in the MOF structure can be reduced to $\mathrm{Co}(\mathrm{I})$ under the electrocatalysis conditions. In another study, a covalent organic framework comprising cobalt porphyrin as building unit can even catalyze the $\mathrm{CO}_{2}$ reduction in water with a much higher turnover frequency than molecular Co catalyst ${ }^{219}$. Covalent organic frameworks seem to be much better than metal-organic frameworks as the support, which could be caused by the different electric conductivity. As we have discussed above in other reactions, the stability of MOF materials under electrocatalytic conditions is always an inevitable issue. In fact, the deformation of the Co-ZIF-67 structure can occur under the reaction conditions for electrocatalytic oxygen evolution and the $\mathrm{CoO}(\mathrm{OH})$ nanoparticles generated from Co-ZIF-67, instead of the Co nodes in the MOF structure, are the working active sites ${ }^{220}$.

Preparing hybrid materials by combing the advantages of various types of materials can be an alternative approach to surpass the current bottleneck for $\mathrm{CO}_{2}$ reduction. Supported functionalized 
cobalt phthalocyanine on carbon nanotubes shows $\sim 40 \%$ efficiency for electrocatalytic $\mathrm{CO}_{2}$ reduction to methanol ${ }^{221}$. The carbon nanotubes serve as the conductive support for charge transfer and also stabilize the molecular Co catalysts. Inspired by this work, if one can generate single-layer metalphthalocyanine MOF that bonded to graphene-type materials, a highly efficient and stable catalyst for $\mathrm{CO}_{2}$ reduction may be produced ${ }^{222,223}$. Extending this concept to a more general scenario, it can be expected that, by engineering the interfacial contact between metal-organic framework materials and the substrate (the conducting support, electrode, etc.) should be a promising strategy to achieve highperformance catalysts.

A larger number of works based on MOF-derived materials have been reported for electrocatalysis, which are mostly prepared by pyrolysis of metal-MOF materials or metal-organic complexes, rather than directly using metal-MOF materials ${ }^{224,225}$. One possible reason can be the higher electric conductivity of the carbon support generated after pyrolysis. Moreover, though the metal species can also be coordinated to four $\mathrm{N}$ atoms as $\mathrm{M}-\mathrm{N}_{4}$ moiety in $\mathrm{MOF}$, the electronic structure of the surrounding environment and the "backbone" material supporting the M-N 4 moiety in MOFs is still different to that in carbon matrix.

If comparing the photocatalytic and electrocatalytic systems that have been developed in the literature with nature's photosynthesis systems, which can convert low-concentration of $\mathrm{CO}_{2}(\sim 400$ ppm) in the atmosphere into biomass, the current efficiency of artificial photosynthesis and electrosynthesis systems is still far behind. It has been shown in some works that, under photo irradiation or in the presence of electric field, the reactivity and stability can be enhanced and the selectivity can also be modulated ${ }^{226,227}$. In particular, the transfer of the charge carriers such as photogenerated electrons/holes and electrons in electric field to the metal species in porous materials will play a vital role. Therefore, the reaction engineering including the reactor design, control of the interface between the porous materials and the electrodes will also bring new opportunities to this field.

\section{Comparison of different catalysts}

\subsection{Influence of support morphology}

In the above examples, we have summarized some typical reactions catalysed by isolated atoms and metal clusters confined in zeolites and MOFs. When comparing the catalytic performance (activity, 
selectivity and stability) of confined metal species in microporous materials with their counterparts supported on open-structured carriers (Figure 6), the advantages of confinement effect usually can be exhibited in reactions involving small molecules such as $\mathrm{CO}, \mathrm{CO}_{2}$ and $\mathrm{CH}_{4}$, due to the diffusion problems for larger reactants in the porous structures. Due to the advantages of microporous materials on adsorption and enrichment of small reactants, the reactivity of the confined metal species can be further enhanced. During the catalytic cycles, the metal species and reactants will be constrained in the limited space inside the porous support, which may change the conformation of the transition state, resulting in unique catalytic behaviour compared to the metal species supported on an open surface. Such geometric confinement effect is clearly shown in the shape selectivity achieved by metal-zeolite catalysts.

Metal entities supported on mesoporous materials and metal nanoparticles encapsulated in microporous materials can be treated as intermediate states between the abovementioned two scenarios. When metal entities are supported on mesoporous materials (MCM-41, SBA-15, porous carbon etc.), their stability against sintering can be improved. Moreover, the lager pore size of mesoporous materials allows the diffusion of larger reactants to the metal sites, resulting a wider reaction scope. On the other hand, the shape-selectivity is also compromised by the larger pore size ${ }^{228,229}$. In the case of metal nanoparticles encapsulated in microporous materials, the shape-selectivity and high stability is preserved by the matrix surrounding the metal nanoparticles ${ }^{63-65,230-232}$. However, due to the mismatch between the metal particles and the micropores, the confinement effect is not maximized. As a result, the structural characterization and precise control of the location of the metal nanoparticles and their surrounding environment is a challenge.

\subsection{Comparison of zeolites and MOFs}

For a specific reaction, it maybe catalysed by either metal-zeolite or metal-MOF materials. By looking into the above exemplary reactions, metal-zeolite materials seem to be more suitable for gas-phase reactions involving small molecules while metal-MOF materials seem to be more suitable for liquid-phase organic reactions. Such difference could be related to the higher stability of zeolites and the diffusion barrier caused by the rigid zeolite framework. The relatively larger pore size and flexibility of the MOF framework improves the accessibility of organic reactants to the metal species.

Another factor causing such difference is the electronic structures of metal species confined in MOFs. 
Metal atoms or clusters confined in zeolites can still be treated as inorganic complexes, whose chemical states are either positively charged or metallic and are similar to those species supported on conventional solid carriers. However, when those metal species are bonded to the nodes or ligands of MOF, unconventional chemical states can be generated. The coordination environment of metal species confined in MOFs are close to the metal complexes used in homogeneous catalysis, making them more suitable for liquid-phase organic reactions such as the production of fine chemicals catalysed by expensive and unstable homogeneous metal complexes in conventional processes ${ }^{233}$. By translating the lessons learnt in homogeneous catalysis on modulating the coordination environment of the metal species, it is possible to achieve unique chemoselectivity for a wide range of organic reactions with metal-MOF catalysts. The advantage of the use of MOF as the container for subnanometric metal species will be more remarkable for photocatalytic reactions involving the combination of photo-redox and metal catalysis since the charge transfer from the light sensitizer to the metal sites can be achieved within the cavity of MOF structure ${ }^{234,235}$. The combination of the electric conductivity and versatile functionality of MOF structure offers the application of metal-MOF materials for the emerging electrocatalytic organic synthesis ${ }^{236}$.

It should be mentioned that, subnanometric metal species can also be incorporated and confined in amorphous porous materials, such as porous polymers or inorganic-organic hybrid materials. So far, the industrial hydroformylation reactions are performed under homogeneous conditions, using molecular Rh-based and Co-based complexes as catalysts. In the last two decades, great efforts have been devoted to transform the conventional homogeneous into heterogeneous systems for convenient separation and recyclability of the catalysts ${ }^{21}$. By encapsulation of Rh complex in zeolites by ship-inbottle synthesis, the hydrogenation of olefins by single-site Rh species in confined space can be achieved. The zeolite structure can also prevent the leaching of $\mathrm{Rh}$ species under reaction conditions and avoid the sintering of $\mathrm{Rh}$ to nanoparticles. However, the rigid structure and small pore size of zeolites will also limit the accessibility of reactants to Rh species. And more importantly, the ratio of linear and branched products is not improved in a substantial manner ${ }^{237}$. Similar catalytic performance has also been reported with Rh confined in MOF materials, indicating the efforts on heterogenized $\mathrm{Rh}$ complex for hydroformylation reaction are not very successful ${ }^{238}$. One possibility is, when using Rhzeolite or Rh-MOF catalysts for the hydroformylation reaction, the active sites are not located inside the crystalline porous materials as expected, thus giving low ratio of linear to branched product ${ }^{239}$. In a recent work, by encapsulating Rh clusters in MFI zeolite, by improving the fraction of Rh clusters 
encapsulated in pure-silica MFI zeolite, regioselectivity to linear butyraldehyde is enhanced from 46 to $83 \%$, indicating the importance of controlling the spatial distribution of active species in microporous materials ${ }^{240}$. To avoid the mass transportation problem, isolated $\mathrm{Rh}$ atoms have been successfully anchored on porous organic polymer from the co-polymerization of vinyl functionalized phosphorus ligands, and these single-atom Rh catalysts showed excellent activity and reusability for hydroformylation of olefins ${ }^{241,242}$. These $\mathrm{Rh}$ atoms showed high TOFs in hydroformylation of propene and high selectivity to linear butaldehyde.

\section{Outlook}

To have precisely control on the location of subnanometric metal species in porous materials at atomic level is a key step to establish structure-reactivity relationship for fundamental understanding on the nature of the active sites. Moreover, such catalysts with uniform structures will also be able to achieve high selectivity in catalytic reactions and high stability if the active sites are well confined inside the porous materials.

For most of the previous works in the literature, the materials were usually prepared and then tested for a couple of potential reactions. Such a trial-and-error research paradigm can be effective and indeed, many catalysts used in the industrial processes were developed in this way ${ }^{243}$. Herein, we would like to propose a complementary paradigm for synthesis of metal catalysts through an "ab initio" concept, in which the structure and coordination environment of the active sites are designed according to the transition state of the target reaction. Such concept has already been demonstrated in aluminosilicate and titanosilicate zeolites for a couple of reactions, in which the zeolite materials are synthesized using organic structure-directing agents with similar structures to the transition states in the target reactions $^{244-246}$. For most of the reactions catalysed by metal-zeolite or metal-MOF materials, especially for those involving organic molecules, the transition state can be described as a coordination complex with a single or multiple metal sites. By mimicking the geometric conformation of the transition state and introduce the corresponding structure into the preparation of metal-zeolite or metalMOF materials, a catalyst with optimized coordination environment for the metal atoms or clusters can be prepared for the desired reaction.

In some of the abovementioned works, the neighbouring metal sites confined in the porous materials 
can work synergistically to activate the reactants or perform reactions that requires multiple metal sites. The longer distance between the neighbouring metal sites are slightly longer than the bonded metal atoms in a single nanoparticles or clusters. The porous structures of zeolite and MOFs can be an ideal host for densely atomically dispersed atoms. Though the unique catalytic behaviour of neighbouring atoms has been demonstrated in several examples, the differences in reaction mechanism compared to the bonded metal atoms in metal clusters or nanoparticles are still not clear. Some questions remain open: how the density of the neighbouring atoms will influence their catalytic performance and whether those neighbouring atoms still remain dispersed under reaction conditions. Thanks to the well-defined structures of the crystalline microporous matrix and the confined metal species, it is possible to carried theoretical calculations to understand how the coordination environment influence the intrinsic structure features of the metal centres and propose representative descriptors for screening potential structures to guide preparation of new catalysts.

It has been shown in some works that, the metal species and the zeolite or MOF framework can work synergistically as bifunctional catalyst. However, up to date, the structural characterization on the location of the two types of active sites and their proximity remains to be a great challenge ${ }^{247}$. Systematically studies are required to understand the reaction mechanism and the formation and transportation of the intermediates between different active sites. On the other hand, to reach a better synergy between the two types of active sites, synthesis methodologies for tuning the proximity of the two types of active sites have to be developed.

The dynamic structural transformation of isolated atoms and metal clusters under reaction conditions has been proved to be common phenomena in heterogeneous catalysis ${ }^{248,249}$. The chemical states and coordination environment of the isolated atoms or clusters confined in porous materials may probably be different to the pristine catalyst. At present, we have limited characterization techniques to directly observe the dynamic structure of the active sites at atomic and molecular level under in situ or operando conditions $s^{250,251}$. Especially, very limited structural information can be obtained in threedimensional scale, which limits our understanding on how the chemical transformation occurs inside the porous materials. Such issue will be even more critical with metal-MOF materials due to their lower stability.

As mentioned before, the scope of the reactions can be limited by the diffusion problems caused by the porous framework. As demonstrated in the literature for hierarchical zeolite and MOF materials, 
the accessibility to the metal sites can be promoted by tuning the size, morphology, porosity of the zeolite and MOF crystallites ${ }^{252-255}$. Furthermore, considering the different physiochemical properties of zeolites and MOFs, by combining the advantage of the two types of crystalline porous materials (zeolites and MOFs) for the synthesis of inorganic-organic hybrid materials, it may lead us to achieve unique reactivity and selectivity for a broader scope of catalytic applications ${ }^{256}$.

In summary, isolated metal atoms and clusters confined in crystalline porous materials are emerging materials with novel catalytic properties. With the accumulation of knowledge and insights, a unified theory to understand catalysis in highly diverse systems, from molecular complexes to solid crystalline solids, from gas phase to liquid phase, from conventional thermal reactions to photocatalytic or electrocatalytic reactions, can be established. And more importantly, heterogeneous catalysts designed by confining subnanometric metal species in porous materials can be applied for industrial processes.

\section{Acknowledgement}

We are grateful for the financial supports from the European Union through the European Research Council (grant ERC-AdG-2014-671093, SynCatMatch) and the Spanish government through the “Severo Ochoa Program” (SEV-2016-0683).

\section{Author Contributions}

L.L. and A.C. wrote this review together.

\section{References}

1. Liu, L. \& Corma, A. Metal Catalysts for Heterogeneous Catalysis: From Singly Atoms to Nanoclusters and Nanoparticles. Chem. Rev. 118, 4981-5079 (2018).

2. Wang, A., Li, J. \& Zhang, T. Heterogeneous single-atom catalysis. Nat. Rev. Chem. 2, 65-81 (2018).

3. Flytzani-Stephanopoulos, M. \& Gates, B. C. Atomically dispersed supported metal catalysts. Ann. Rev. Chem. Biomol. Eng. 3, 545-574 (2012).

4. Takei, T. et al. Heterogeneous Catalysis by Gold. Adv. Catal. 55, 1-126 (2012).

5. Xu, Z. et al. Size-dependent catalytic activity of supported metal clusters. Nature 372, 346-348 (1994).

6. Valden, M., Lai, X. \& Goodman, D. W. Onset of catalytic activity of gold clusters on titania with the appearance of nonmetallic properties. Science 281, 1647-1650 (1998).

7. Boronat, M., Leyva-Perez, A. \& Corma, A. Theoretical and experimental insights into the origin of the catalytic activity of subnanometric gold clusters: attempts to predict reactivity with clusters and nanoparticles of gold. Acc. Chem. Res. 47, 834-844 (2014). 
8. Liu, L. et al. Determination of the Evolution of Heterogeneous Single Metal Atoms and Nanoclusters under Reaction Conditions: Which Are the Working Catalytic Sites? ACS Catal., 10626-10639 (2019).

9. Gates, B. C., Flytzani-Stephanopoulos, M., Dixon, D. A. \& Katz, A. Atomically dispersed supported metal catalysts: perspectives and suggestions for future research. Catalysis Science \& Technology 7, 4259-4275 (2017).

10. Sachtler, W. M. H. Metal clusters in zeolites: an intriguing class of catalysts. Acc. Chem. Res. 26, 383387 (1993).

11. Kosinov, N., Liu, C., Hensen, E. J. M. \& Pidko, E. A. Engineering of Transition Metal Catalysts Confined in Zeolites. Chem. Mater. 30, 3177-3198 (2018).

12. Rogge, S. M. J. et al. Metal-organic and covalent organic frameworks as single-site catalysts. Chem. Soc. Rev. 46, 3134-3184 (2017).

13. Parkinson, G. S. Single-Atom Catalysis: How Structure Influences Catalytic Performance. Catal. Lett. 149, 1137-1146 (2019).

14. Fako, E., Łodziana, Z. \& López, N. Comparative single atom heterogeneous catalysts (SAHCs) on different platforms: a theoretical approach. Catal. Sci. Technol. 7, 4285-4293 (2017).

15. Hu, P. et al. Electronic metal-support interactions in single-atom catalysts. Angew. Chem. Int. Ed. 53, 3418-3421 (2014).

16. Coperet, C. et al. Surface Organometallic and Coordination Chemistry toward Single-Site Heterogeneous Catalysts: Strategies, Methods, Structures, and Activities. Chem. Rev. 116, 323-421 (2016).

17. Pelletier, J. D. \& Basset, J. M. Catalysis by Design: Well-Defined Single-Site Heterogeneous Catalysts. Acc. Chem. Res. 49, 664-677 (2016).

18. Yin, P. et al. Single Cobalt Atoms with Precise N-Coordination as Superior Oxygen Reduction Reaction Catalysts. Angew. Chem. Int. Ed. 55, 10800-10805 (2016).

19. Chen, Z. et al. Tunability and Scalability of Single-Atom Catalysts Based on Carbon Nitride. ACS Sustainable Chem. Eng. 7, 5223-5230 (2019).

20. Hoffman, A. S. et al. Beating Heterogeneity of Single-Site Catalysts: MgO-Supported Iridium Complexes. ACS Catal. 8, 3489-3498 (2018).

21. De Vos, D. E., Dams, M., Sels, B. F. \& Jacobs, P. A. Ordered Mesoporous and Microporous Molecular Sieves Functionalized with Transition Metal Complexes as Catalysts for Selective Organic Transformations. Chem. Rev. 102, 3615-3640 (2002).

22. Ozin, G. A. \& Gil, C. Intrazeolite organometallics and coordination complexes: internal versus external confinement of metal guests. Chem. Rev. 89, 1749-1764 (1989).

23. Martini, A. et al. Composition-driven $\mathrm{Cu}$-speciation and reducibility in $\mathrm{Cu}-\mathrm{CHA}$ zeolite catalysts: a multivariate XAS/FTIR approach to complexity. Chem. Sci. 8, 6836-6851 (2017).

24. Khivantsev, K. et al. Effect of Si/Al Ratio and Rh Precursor Used on the Synthesis of HY ZeoliteSupported Rhodium Carbonyl Hydride Complexes. J. Phys. Chem. C 119, 17166-17181 (2015).

25. Moreno-González, M., Millán, R., Concepción, P., Blasco, T. \& Boronat, M. Spectroscopic Evidence and Density Functional Theory (DFT) Analysis of Low-Temperature Oxidation of $\mathrm{Cu}^{+}$to $\mathrm{Cu}^{2+} \mathrm{NOx}$ in Cu-CHA Catalysts: Implications for the SCR-NOx Reaction Mechanism. ACS Catal. 9, 2725-2738 (2019).

26. Borfecchia, E. et al. Cu-CHA - a model system for applied selective redox catalysis. Chem. Soc. Rev. 47, 8097-8133 (2018).

27. Ji, P., Feng, X., Veroneau, S. S., Song, Y.\& Lin, W. Trivalent Zirconium and Hafnium Metal-Organic 
Frameworks for Catalytic 1,4-Dearomative Additions of Pyridines and Quinolines. J. Am. Chem. Soc. 139, 15600-15603 (2017).

28. Bernales, V., Ortuno, M. A., Truhlar, D. G., Cramer, C. J. \& Gagliardi, L. Computational Design of Functionalized Metal-Organic Framework Nodes for Catalysis. ACS Cent. Sci. 4, 5-19 (2018).

29. Liu, K. et al. Genesis of electron deficient $\mathrm{Pt}_{1}(0)$ in PDMS-PEG aggregates. Nat. Commun. 10, 996 (2019).

30. Sun, G., Alexandrova, A. N. \& Sautet, P. Pt 8 cluster on alumina under a pressure of hydrogen: Support-dependent reconstruction from first-principles global optimization. J. Chem. Phys. 151, 194703 (2019).

31. Tosoni, S. \& Pacchioni, G. Oxide-Supported Gold Clusters and Nanoparticles in Catalysis: A Computational Chemistry Perspective. ChemCatChem 11, 73-89 (2018).

32. Stakheev, A. Y. \& Kustov, L. M. Effects of the support on the morphology and electronic properties of supported metal clusters: modern concepts and progress in 1990s. Appl. Catal. A: Gen. 188, 3-35 (1999).

33. Vilhelmsen, L. B., Walton, K. S. \& Sholl, D. S. Structure and mobility of metal clusters in MOFs: Au, Pd, and AuPd clusters in MOF-74. J. Am. Chem. Soc. 134, 12807-12816 (2012).

34. Tian, Z. et al. Theoretical Evidence on the Confinement Effect of Pt@UiO-66- $\mathrm{NH}_{2}$ for Cinnamaldehyde Hydrogenation. J. Phys. Chem. C 123, 22114-22122 (2019).

35. Dou, L. et al. Structures and Electronic Properties of Au Clusters Encapsulated ZIF-8 and ZIF-90. J. Phys. Chem. C 122, 8901-8909 (2018).

36. Xiao, J., Pan, X., Zhang, F., Li, H. \& Bao, X. Size-dependence of carbon nanotube confinement in catalysis. Chem. Sci. 8, 278-283 (2017).

37. Xiao, J., Pan, X., Guo, S., Ren, P. \& Bao, X. Toward fundamentals of confined catalysis in carbon nanotubes. J. Am. Chem. Soc. 137, 477-482 (2015).

38. Hakkinen, H. Atomic and electronic structure of gold clusters: understanding flakes, cages and superatoms from simple concepts. Chem. Soc. Rev. 37, 1847-1859 (2008).

39. Ferrari, A. M., Neyman, K. M., Belling, T., Mayer, M. \& Rösch, N. Small Platinum Clusters in Zeolites: A Density Functional Study of CO Adsorption on Electronically Modified Models. J. Phys. Chem. B 103, 216-226 (1999).

40. Ferrari, A. M. et al. Faujasite-Supported Ir $_{4}$ Clusters: A Density Functional Model Study of Metal-Zeolite Interactions. J. Phys. Chem. B 103, 5311-5319 (1999).

41. Boronat, M. \& Corma, A. What Is Measured When Measuring Acidity in Zeolites with Probe Molecules? ACS Catal. 9, 1539-1548 (2019).

42. Gounder, R. \& Iglesia, E. The roles of entropy and enthalpy in stabilizing ion-pairs at transition states in zeolite acid catalysis. Acc. Chem. Res. 45, 229-238 (2012).

43. Eckstein, S. et al. Influence of Hydronium Ions in Zeolites on Sorption. Angew. Chem. Int. Ed. 58, 3450-3455 (2019).

44. Latimer, A. A. et al. Understanding trends in C-H bond activation in heterogeneous catalysis. Nat. Mater. 16, 225-229 (2017).

45. Wannakao, S., Maihom, T., Probst, M., Limtrakul, J. \& Kongpatpanich, K. Porous Materials as a Platform for Highly Uniform Single-Atom Catalysts: Tuning the Electronic Structure for the LowTemperature Oxidation of Carbon Monoxide. J. Phys. Chem. C 120, 19686-19697 (2016).

46. Koningsberger, D. C., de Graaf, J., Mojet, B. L., Ramaker, D. E. \& Miller, J. T. The metal-support interaction in $\mathrm{Pt} / \mathrm{Y}$ zeolite: evidence for a shift in energy of metal d-valence orbitals by $\mathrm{Pt}-\mathrm{H}$ shape 
resonance and atomic XAFS spectroscopy. Appl. Catal. A: Gen. 191, 205-220 (2000).

47. Treesukol, P., Srisuk, K., Limtrakul, J. \& Truong, T. N. Nature of the metal-support interaction in bifunctional catalytic Pt/H-ZSM-5 zeolite. J. Phys. Chem. B 109, 11940-11945 (2005).

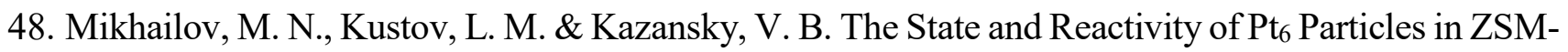
5 Zeolite. Catal. Lett. 120, 8-13 (2007).

49. Grybos, R., Benco, L., Bucko, T. \& Hafner, J. Molecular adsorption and metal-support interaction for transition-metal clusters in zeolites: NO adsorption on Pdn (n=1-6) clusters in mordenite. J. Chem. Phys. 130, 104503 (2009).

50. Mahyuddin, M. H., Staykov, A., Shiota, Y., Miyanishi, M. \& Yoshizawa, K. Roles of Zeolite Confinement and $\mathrm{Cu}-\mathrm{O}-\mathrm{Cu}$ Angle on the Direct Conversion of Methane to Methanol by $\left[\mathrm{Cu}_{2}(\mu-\right.$ O) $]^{2+}$-Exchanged AEI, CHA, AFX, and MFI Zeolites. ACS Catal. 7, 3741-3751 (2017).

51. Szécsényi, Á. et al. Breaking Linear Scaling Relationships with Secondary Interactions in Confined Space: A Case Study of Methane Oxidation by Fe/ZSM-5 Zeolite. ACS Catal. 9, 9276-9284 (2019).

52. Choi, M., Yook, S. \& Kim, H. Hydrogen Spillover in Encapsulated Metal Catalysts: New Opportunities for Designing Advanced Hydroprocessing Catalysts. ChemCatChem 7, 1048-1057 (2015).

53. Im, J., Shin, H., Jang, H., Kim, H. \& Choi, M. Maximizing the catalytic function of hydrogen spillover in platinum-encapsulated aluminosilicates with controlled nanostructures. Nat. Commun. 5, 3370 (2014).

54. Goellner, J. F., Gates, B. C., Vayssilov, G. N. \& Rösch, N. Structure and Bonding of a Site-Isolated Transition Metal Complex: Rhodium Dicarbonyl in Highly Dealuminated Zeolite Y. J. Am. Chem. Soc. 122, 8056-8066 (2000).

55. de Graaf, J., van Dillen, A. J., de Jong, K. P. \& Koningsberger, D. C. Preparation of Highly Dispersed Pt Particles in Zeolite Y with a Narrow Particle Size Distribution: Characterization by Hydrogen Chemisorption, TEM, EXAFS Spectroscopy, and Particle Modeling. J. Catal. 203, 307-321 (2001).

56. Schreier, M., Teren, S., Belcher, L., Regalbuto, J. R. \& Miller, J. T. The nature of 'overexchanged' copper and platinum on zeolites. Nanotechnology 16, S582-S591 (2005).

57. Serna, P. \& Gates, B. C. Molecular metal catalysts on supports: organometallic chemistry meets surface science. Acc. Chem. Res. 47, 2612-2620 (2014).

58. Zecevic, J., van der Eerden, A. M., Friedrich, H., de Jongh, P. E. \& de Jong, K. P. Heterogeneities of the nanostructure of platinum/zeolite y catalysts revealed by electron tomography. ACS Nano 7, 36983705 (2013).

59. Balkus K.J., Gabrielov A.G. (1995) Zeolite Encapsulated Metal Complexes. In: Herron N., Corbin D.R. (eds) Inclusion Chemistry with Zeolites: Nanoscale Materials by Design. Topics in Inclusion Science, vol 6. Springer, Dordrecht.

60. Kawi, S. \& Gates, B.C. (1994) Clusters in Cages. In: Clusters and Colloids. From Theory to Applications, Wiley.

61. Corma, A. \& Garcia, H. Supramolecular Host-Guest Systems in Zeolites Prepared by Ship-in-a-Bottle Synthesis. Eur. J. Inorg. Chem. 2004, 1143-1164 (2004).

62. Kuehl, G. H. Shape selective catalyst from zeolite alpha and use thereof, US patent 4,299,686 (1986).

63. Choi, M., Wu, Z. \& Iglesia, E. Mercaptosilane-assisted synthesis of metal clusters within zeolites and catalytic consequences of encapsulation. J. Am. Chem. Soc. 132, 9129-9137 (2010).

64. Goel, S., Wu, Z., Zones, S. I. \& Iglesia, E. Synthesis and catalytic properties of metal clusters encapsulated within small-pore (SOD, GIS, ANA) zeolites. J. Am. Chem. Soc. 134, 17688-17695 
(2012).

65. Wang, N. et al. In Situ Confinement of Ultrasmall Pd Clusters within Nanosized Silicalite-1 Zeolite for Highly Efficient Catalysis of Hydrogen Generation. J. Am. Chem. Soc. 138, 7484-7487 (2016).

66. Moliner, M. et al. Reversible Transformation of Pt Nanoparticles into Single Atoms inside HighSilica Chabazite Zeolite. J. Am. Chem. Soc. 138, 15743-15750 (2016).

67. Liu, Y. et al. A General Strategy for Fabricating Isolated Single Metal Atomic Site Catalysts in Y Zeolite. J. Am. Chem. Soc. 141, 9305-9311 (2019).

68. Sun, Q. et al. Zeolite-Encaged Single-Atom Rhodium Catalysts: Highly-Efficient Hydrogen Generation and Shape-Selective Tandem Hydrogenation of Nitroarenes. Angew. Chem. Int. Ed. (2019), doi: 10.1002/anie.201912367.

69. Liu, L. et al. Generation of subnanometric platinum with high stability during transformation of a 2D zeolite into 3D. Nat. Mater. 16, 132-138 (2017).

70. Zhang, Y., Kubů, M., Mazur, M. \& Čejka, J. Encapsulation of Pt nanoparticles into IPC-2 and IPC-4 zeolites using the ADOR approach. Microporous Mesoporous Mater. 279, 364-370 (2019).

71. Moliner, M., Gabay, J., Kliewer, C., Serna, P. \& Corma, A. Trapping of Metal Atoms and Metal Clusters by Chabazite under Severe Redox Stress. ACS Catal. 8, 9520-9528 (2018).

72. Liu, L. et al. Evolution and stabilization of subnanometric metal species in confined space by in situ TEM. Nat. Commun. 9, 574 (2018).

73. Liu, L. et al. Regioselective generation and reactivity control of subnanometric platinum clusters in zeolites for high-temperature catalysis. Nat. Mater. 18, 866-873 (2019).

74. Zhang, X. et al. Catalytic chemoselective functionalization of methane in a metal-organic framework. Nat. Catal. 1, 356-362 (2018).

75. Brozek, C. K. \& Dinca, M. $\mathrm{Ti}^{3+}-, \mathrm{V}^{2+/ 3+}-, \mathrm{Cr}^{2+/ 3+}-, \mathrm{Mn}^{2+}$, and $\mathrm{Fe}^{2+}$-substituted MOF-5 and redox reactivity in Cr- and Fe-MOF-5. J. Am. Chem. Soc. 135, 12886-12891 (2013).

76. Shultz, A. M., Sarjeant, A. A., Farha, O. K., Hupp, J. T. \& Nguyen, S. T. Post-synthesis modification of a metal-organic framework to form metallosalen-containing MOF materials. J. Am. Chem. Soc. 133, 13252-13255 (2011).

77. Yang, D. \& Gates, B. C. Catalysis by Metal Organic Frameworks: Perspective and Suggestions for Future Research. ACS Catal. 9, 1779-1798 (2019).

78. Kim, I. S. et al. Sinter-Resistant Platinum Catalyst Supported by Metal-Organic Framework. Angew. Chem. Int. Ed. 57, 909-913 (2018).

79. Luo, Y. et al. Fabrication of $\mathrm{Au}_{25}(\mathrm{SG})_{18}-\mathrm{ZIF}-8$ Nanocomposites: A Facile Strategy to Position $\mathrm{Au}_{25}(\mathrm{SG})_{18}$ Nanoclusters Inside and Outside ZIF-8. Adv. Mater. 30, 1704576 (2018).

80. Kratzl, K. et al. Generation and Stabilization of Small Platinum Clusters $\mathrm{Pt}_{12 \pm \mathrm{x}}$ Inside a Metal-Organic Framework. J. Am. Chem. Soc. 141, 13962-13969 (2019).

81. Fortea-Perez, F. R. et al. The MOF-driven synthesis of supported palladium clusters with catalytic activity for carbene-mediated chemistry. Nat. Mater. 16, 760-766 (2017).

82. Mon, M. et al. Synthesis of Densely Packaged, Ultrasmall $\mathrm{Pt}_{0}{ }^{2}$ Clusters within a ThioetherFunctionalized MOF: Catalytic Activity in Industrial Reactions at Low Temperature. Angew. Chem. Int. Ed. 57, 6186-6191 (2018).

83. Sá, J. et al. Redispersion of Gold Supported on Oxides. ACS Catal. 2, 552-560 (2012).

84. Varela, M. et al. Materials Characterization in the Aberration-Corrected Scanning Transmission Electron Microscope. Annu. Rev. Mater. Res. 35, 539-569 (2005).

85. Zhou, W., Wachs, I. E. \& Kiely, C. J. Nanostructural and chemical characterization of supported 
metal oxide catalysts by aberration corrected analytical electron microscopy. Current Opinion Solid State Mater. Sci. 16, 10-22 (2012).

86. Gates, B. C. Atomically Dispersed Supported Metal Catalysts: Seeing Is Believing. Trends Chem. 1, 99-110 (2019).

87. Lu, J., Aydin, C., Browning, N. D. \& Gates, B. C. Imaging isolated gold atom catalytic sites in zeolite NaY. Angew. Chem. Int. Ed. 51, 5842-5846 (2012).

88. Liu, L. et al. Direct Imaging of Atomically Dispersed Molybdenum that Enables Locating Aluminum in the Framework of Zeolite ZSM-5. Angew. Chem. Int. Ed. (2019), doi: 10.1002/anie.201909834.

89. Fang, X. et al. Single Pt Atoms Confined into a Metal-Organic Framework for Efficient Photocatalysis. Adv. Mater. 30 (2018).

90. Rivero-Crespo, M. A. et al. Confined $\mathrm{Pt}_{1}{ }^{+}$Water Clusters in a MOF Catalyze the Low-Temperature Water-Gas Shift Reaction with both $\mathrm{CO}_{2}$ Oxygen Atoms Coming from Water. Angew. Chem. Int. Ed. 57, 17094-17099 (2018).

91. Li, Y. et al. Cryo-EM Structures of Atomic Surfaces and Host-Guest Chemistry in Metal-Organic Frameworks. Matter 1, 428-438 (2019).

92. Henninen, T. R., Bon, M., Wang, F., Passerone, D. \& Erni, R. The Structure of Sub-nm Platinum Clusters at Elevated Temperatures. Angew. Chem. Int. Ed. 2019, doi: 10.1002/anie.201911068.

93. Miao, J., Ercius, P. \& Billinge, S. J. Atomic electron tomography: 3D structures without crystals. Science 353 (2016).

94. Wang, X. N. et al. Crystallographic Visualization of Post-synthetic Nickel Clusters into MetalOrganic Framework. J. Am. Chem. Soc. 141, 13654-13663 (2019).

95. Lovejoy, T. C. et al. Single atom identification by energy dispersive X-ray spectroscopy. Applied Physics Letters 100, 154101 (2012).

96. Chung, H. T. et al. Direct atomic-level insight into the active sites of a high-performance PGMfree ORR catalyst. Science 357, 479-484 (2017).

97. Tizei, L. H. G. et al. Single atom spectroscopy: Decreased scattering delocalization at high energy losses, effects of atomic movement and X-ray fluorescence yield. Ultramicroscopy 160, 239-246 (2016).

98. Seidman, D. N. Three-Dimensional Atom-Probe Tomography: Advances and Applications. Annu. Rev. Mater. Res. 37, 127-158 (2007).

99. Barroo, C., Akey, A. J. \& Bell, D. C. Atom Probe Tomography for Catalysis Applications: A Review. Appl. Sci. 9, 2721 (2019).

100. Perea, D. E. et al. Determining the location and nearest neighbours of aluminium in zeolites with atom probe tomography. Nat. Commun. 6, 7589 (2015).

101. Schmidt, J. E., Oord, R., Guo, W., Poplawsky, J. D. \& Weckhuysen, B. M. Nanoscale tomography reveals the deactivation of automotive copper-exchanged zeolite catalysts. Nat. Commun. 8, 1666 (2017).

102. Jiang, K. et al. Transition-Metal Singly Atoms in a Graphene Shell as Active Centers for Highly Efficient Artificial Photosynthesis. Chem 3, 950-960 (2017).

103. Schmidt, J. E., Peng, L., Poplawsky, J. D. \& Weckhuysen, B. M. Nanoscale Chemical Imaging of Zeolites Using Atom Probe Tomography. Angew. Chem. Int. Ed. 57, 10422-10435 (2018).

104. Timoshenko, J., Duan, Z., Henkelman, G., Crooks, R. M. \& Frenkel, A. I. Solving the Structure and Dynamics of Metal Nanoparticles by Combining X-Ray Absorption Fine Structure 
Spectroscopy and Atomistic Structure Simulations. Annu. Rev. Anal. Chem. 12, 501-522 (2019).

105. Kulkarni, A., Chi, M., Ortalan, V., Browning, N. D. \& Gates, B. C. Atomic resolution of the structure of a metal-support interface: triosmium clusters on $\mathrm{MgO}(110)$. Angew. Chem. Int. Ed. 49, 10089-10092 (2010).

106. Marberger, A. et al. Time-resolved copper speciation during selective catalytic reduction of NO on Cu-SSZ-13. Nat. Catal. 1, 221-227 (2018).

107. Yuan, N. et al. Probing the Evolution of Palladium Species in Pd@MOF Catalysts during the Heck Coupling Reaction: An Operando X-ray Absorption Spectroscopy Study. J. Am. Chem. Soc. 140, 8206-8217 (2018).

108. Timoshenko, J. \& Frenkel, A. I. "Inverting” X-ray Absorption Spectra of Catalysts by Machine Learning in Search for Activity Descriptors. ACS Catal. 9, 10192-10211 (2019).

109. Timoshenko, J. et al. Subnanometer Substructures in Nanoassemblies Formed from Clusters under a Reactive Atmosphere Revealed Using Machine Learning. J. Phys. Chem. C 122, 21686-21693 (2018).

110. Timoshenko, J. et al. Probing Atomic Distributions in Mono- and Bimetallic Nanoparticles by Supervised Machine Learning. Nano Lett. 19, 520-529 (2019).

111. Göltl, F. et al. UV-Vis and Photoluminescence Spectroscopy to Understand the Coordination of Cu Cations in the Zeolite SSZ-13. Chem. Mater. 2019, doi: 10.1021/acs.chemmater.9b01439.

112. Fenwick, O. et al. Tuning the energetics and tailoring the optical properties of silver clusters confined in zeolites. Nat. Mater. 15, 1017-1022 (2016).

113. Shimizu, K.-i. et al. Formation and Redispersion of Silver Clusters in Ag-MFI Zeolite as Investigated by Time-Resolved QXAFS and UV-Vis. J. Phys. Chem. C 111, 1683-1688 (2007).

114. Thang, H. V., Pacchioni, G., DeRita, L. \& Christopher, P. Nature of stable single atom Pt catalysts dispersed on anatase $\mathrm{TiO}_{2}$. J. Catal. 367, 104-114 (2018).

115. Stakheev, A. Y., Shpiro, E. S., Jaeger, N. I. \& Schulz-Ekloff, G. Electronic state and location of Pt metal clusters in KL zeolite: FTIR study of CO chemisorption. Catal. Lett. 32, 147-158 (1995).

116. Hoffman, A. S., Fang, C. Y. \& Gates, B. C. Homogeneity of Surface Sites in Supported SingleSite Metal Catalysts: Assessment with Band Widths of Metal Carbonyl Infrared Spectra. J. Phys. Chem. Lett. 7, 3854-3860 (2016).

117. Lucier, B. E. G., Chen, S. \& Huang, Y. Characterization of Metal-Organic Frameworks: Unlocking the Potential of Solid-State NMR. Acc. Chem. Res. 51, 319-330 (2018).

118. Lewis, J. D. et al. Distinguishing Active Site Identity in Sn-Beta Zeolites Using ${ }^{31} \mathrm{P}$ MAS NMR of Adsorbed Trimethylphosphine Oxide. ACS Catal. 8, 3076-3086 (2018).

119. Brunner, E. \& Rauche, M. Solid-state NMR spectroscopy: An advancing tool to analyse structure and properties of metal-organic frameworks. Chem. Sci. (2020), doi: 10.1039/d0sc00735h.

120. Sun, Q. et al. Subnanometer Bimetallic Pt-Zn Clusters in Zeolites for Propane Dehydrogenation. Angew. Chem. Int. Ed. (2020), doi: 10.1002/anie.202003349.

121. Juneau, M. et al. Characterization of Metal-zeolite Composite Catalysts: Determining the Environment of the Active Phase. ChemCatChem 12, 1826-1852 (2020).

122. Nemeth, L. \& Bare, S. R. Science and Technology of Framework Metal-Containing Zeotype Catalysts. Adv. Catal. 57, 1-97 (2014).

123. Pal, D. B., Chand, R., Upadhyay, S. N. \& Mishra, P. K. Performance of water gas shift reaction catalysts: A review. Renewable Sustainable Energy Rev. 93, 549-565 (2018). 
124. Yang, M. et al. Catalytically active $\mathrm{Au}-\mathrm{O}(\mathrm{OH}) \mathrm{x}$-species stabilized by alkali ions on zeolites and mesoporous oxides. Science 346, 1498-1501 (2014).

125. Yang, M. et al. A common single-site $\mathrm{Pt}(\mathrm{II})-\mathrm{O}(\mathrm{OH}) \mathrm{x}$ - species stabilized by sodium on "active" and "inert" supports catalyzes the water-gas shift reaction. J. Am. Chem. Soc. 137, 3470-3473 (2015).

126. Carter, J. H. et al. Activation and Deactivation of Gold/Ceria-Zirconia in the LowTemperature Water-Gas Shift Reaction. Angew. Chem. Int. Ed. 56, 16037-16041 (2017).

127. Schwach, P., Pan, X. \& Bao, X. Direct Conversion of Methane to Value-Added Chemicals over Heterogeneous Catalysts: Challenges and Prospects. Chem. Rev. 117, 8497-8520 (2017).

128. Huang, K., Miller, J. B., Huber, G. W., Dumesic, J. A. \& Maravelias, C. T. A General Framework for the Evaluation of Direct Nonoxidative Methane Conversion Strategies. Joule 2, 349-365 (2018).

129. Wang, L. et al. Dehydrogenation and aromatization of methane under non-oxidizing conditions. Catal. Lett. 21, 35-41 (1993).

130. Ding, W., Li, S., D Meitzner, G. \& Iglesia, E. Methane Conversion to Aromatics on Mo/HZSM5: Structure of Molybdenum Species in Working Catalysts. J. Phys. Chem. B 105, 506-513 (2001).

131. Kumar, A., Song, K., Liu, L., Han, Y. \& Bhan, A. Absorptive Hydrogen Scavenging for Enhanced Aromatics Yield During Non-oxidative Methane Dehydroaromatization on Mo/H-ZSM5 Catalysts. Angew. Chem. Int. Ed. 57, 15577-15582 (2018).

132. Li, G., Vollmer, I., Liu, C., Gascon, J. \& Pidko, E. A. Structure and Reactivity of the Mo/ZSM5 Dehydroaromatization Catalyst: An Operando Computational Study. ACS Catal. 9, 8731-8737 (2019).

133. Ismagilov, Z. R., Matus, E. V. \& Tsikoza, L. T. Direct conversion of methane on Mo/ZSM-5 catalysts to produce benzene and hydrogen: achievements and perspectives. Energy Environ. Sci. 1, 526 (2008).

134. Spivey, J. J. \& Hutchings, G. Catalytic aromatization of methane. Chem. Soc. Rev. 43, 792803 (2014).

135. Morejudo, S. H. et al. Direct conversion of methane to aromatics in a catalytic co-ionic membrane reactor. Science 353, 563-566 (2016).

136. Hou, Y., Ogasawara, S., Fukuoka, A. \& Kobayashi, H. Zeolite-supported rhodium sub-nano cluster catalyst for low-temperature selective oxidation of methane to syngas. Catal. Sci. Technol. 7, 6132-6139 (2017).

137. Ravi, M. et al. Misconceptions and challenges in methane-to-methanol over transition-metalexchanged zeolites. Nat. Catal. 2, 485-494 (2019).

138. Ravi, M., Ranocchiari, M. \& van Bokhoven, J. A. The Direct Catalytic Oxidation of Methane to Methanol-A Critical Assessment. Angew. Chem. Int. Ed. 56, 16464-16483 (2017).

139. Sushkevich, V. L., Palagin, D., Ranocchiari, M. \& van Bokhoven, J. A. Selective anaerobic oxidation of methane enables direct synthesis of methanol. Science 356, 523-527 (2017).

140. Narsimhan, K., Iyoki, K., Dinh, K. \& Roman-Leshkov, Y. Catalytic Oxidation of Methane into Methanol over Copper-Exchanged Zeolites with Oxygen at Low Temperature. ACS Cent. Sci. 2, 424-429 (2016).

141. Dinh, K. T. et al. Continuous Partial Oxidation of Methane to Methanol Catalyzed by Diffusion-Paired Copper Dimers in Copper-Exchanged Zeolites. J. Am. Chem. Soc. 141, 11641- 


\section{0 (2019).}

142. Ikuno, T. et al. Methane Oxidation to Methanol Catalyzed by Cu-Oxo Clusters Stabilized in NU-1000 Metal-Organic Framework. J. Am. Chem. Soc. 139, 10294-10301 (2017).

143. Zheng, J. et al. Selective Methane Oxidation to Methanol on Cu-Oxo Dimers Stabilized by Zirconia Nodes of an NU-1000 Metal-Organic Framework. J. Am. Chem. Soc. 141, 9292-9304 (2019).

144. Grundner, S. et al. Single-site trinuclear copper oxygen clusters in mordenite for selective conversion of methane to methanol. Nat. Commun. 6, 7546 (2015).

145. Bozbag, S. E. et al. Direct Stepwise Oxidation of Methane to Methanol over $\mathrm{Cu}-\mathrm{SiO}_{2}$. ACS Catal. 8, 5721-5731 (2018).

146. Meyet, J. et al. Monomeric Copper(II) Sites Supported on Alumina Selectively Convert Methane to Methanol. Angew. Chem. Int. Ed. 58, 9841-9845 (2019).

147. Ross, M. O. et al. Particulate methane monooxygenase contains only mononuclear copper centers. Science 364, 566-570 (2019).

148. Shan, J., Li, M., Allard, L. F., Lee, S. \& Flytzani-Stephanopoulos, M. Mild oxidation of methane to methanol or acetic acid on supported isolated rhodium catalysts. Nature 551, 605-608 (2017).

149. Tang, Y. et al. Single rhodium atoms anchored in micropores for efficient transformation of methane under mild conditions. Nat. Commun. 9, 1231 (2018).

150. Bruijnincx, P. C. \& Weckhuysen, B. M. Shale gas revolution: an opportunity for the production of biobased chemicals? Angew. Chem. Int. Ed. 52, 11980-11987 (2013).

151. Stangland, E. E. Shale Gas Implications for C2-C3 Olefin Production: Incumbent and Future Technology. Annu. Rev. Chem. Biomol. Eng., 15.11-15.24 (2018).

152. Li, Z. et al. Metal-Organic Framework Supported Cobalt Catalysts for the Oxidative Dehydrogenation of Propane at Low Temperature. ACS Cent. Sci. 3, 31-38 (2017).

153. Fukunaga, T. \& Katsuno, H. Halogen-promoted Pt/KL Zeolite Catalyst for the Production of Aromatic Hydrocarbons from Light Naphtha. Catal. Surv. Asia 14, 96-102 (2010).

154. Meriaudeau, P. \& Naccache, C. Dehydrocyclization of Alkanes Over Zeolite-Supported Metal Catalysts: Monofunctional or Bifunctional Route. Catal. Rev. 39, 5-48 (1997).

155. $\mathrm{Xu}, \mathrm{D}$. et al. Tailoring Pt locations in KL zeolite by improved atomic layer deposition for excellent performance in n-heptane aromatization. J. Catal. 365, 163-173 (2018).

156. Yang, D. et al. Tuning $\mathrm{Zr}_{6}$ Metal-Organic Framework (MOF) Nodes as Catalyst Supports: Site Densities and Electron-Donor Properties Influence Molecular Iridium Complexes as Ethene Conversion Catalysts. ACS Catal. 6, 235-247 (2015).

157. Liu, J. et al. Introducing Nonstructural Ligands to Zirconia-like Metal-Organic Framework Nodes To Tune the Activity of Node-Supported Nickel Catalysts for Ethylene Hydrogenation. ACS Catal. 9, 3198-3207 (2019).

158. Song, Y. et al. Metal-Organic Framework Nodes Support Single-Site Nickel(II) Hydride Catalysts for the Hydrogenolysis of Aryl Ethers. ACS Catal. 9, 1578-1583 (2019).

159. He, J., Zhao, C. \& Lercher, J. A. Ni-catalyzed cleavage of aryl ethers in the aqueous phase. $J$. Am. Chem. Soc. 134, 20768-20775 (2012).

160. Ji, P. et al. Single-Site Cobalt Catalysts at New $\mathrm{Zr}_{12}\left(\mu_{3}-\mathrm{O}\right)_{8}\left(\mu_{3}-\mathrm{OH}\right)_{8}\left(\mu_{2}-\mathrm{OH}\right)_{6}$ Metal-Organic Framework Nodes for Highly Active Hydrogenation of Nitroarenes, Nitriles, and Isocyanides. $J$. Am. Chem. Soc. 139, 7004-7011 (2017). 
161. Liu, W.; Zhang, L.; Yan, W.; Liu, X.; Yang, X.; Miao, S.; Wang, W.; Wang, A.; Zhang, T. Single-atom dispersed Co-N-C catalyst: structure identification and performance for hydrogenative coupling of nitroarenes. Chem. Sci. 2016, 7, 5758-5764.

162. Westerhaus, F. A.; Jagadeesh, R. V.; Wienhofer, G.; Pohl, M. M.; Radnik, J.; Surkus, A. E.; Rabeah, J.; Junge, K.; Junge, H.; Nielsen, M.et al. Heterogenized cobalt oxide catalysts for nitroarene reduction by pyrolysis of molecularly defined complexes. Nat. Chem. 2013, 5, 537-543.

163. Liu, L.; Gao, F.; Concepción, P.; Corma, A. A new strategy to transform mono and bimetallic non-noble metal nanoparticles into highly active and chemoselective hydrogenation catalysts. $J$. Catal. 2017, 350, 218-225.

164. Liu, L., Concepción, P. \& Corma, A. Non-noble metal catalysts for hydrogenation: A facile method for preparing Co nanoparticles covered with thin layered carbon. J. Catal. 340, 1-9 (2016).

165. Ji, S. et al. Atomically Dispersed Ruthenium Species Inside Metal-Organic Frameworks: Combining the High Activity of Atomic Sites and the Molecular Sieving Effect of MOFs. Angew. Chem. Int. Ed. 58, 4271-4275 (2019).

166. An, B. et al. Cooperative copper centres in a metal-organic framework for selective conversion of $\mathrm{CO}_{2}$ to ethanol. Nat. Catal. 2, 709-717 (2019).

167. Im, J., Shin, H., Jang, H., Kim, H. \& Choi, M. Maximizing the catalytic function of hydrogen spillover in platinum-encapsulated aluminosilicates with controlled nanostructures.

Nat. Commun. 5, 3370 (2014).

168. Cheng, K. et al. Impact of the Spatial Organization of Bifunctional Metal-Zeolite Catalysts on the Hydroisomerization of Light Alkanes. Angew. Chem. Int. Ed. 59, 3592-3600 (2020).

169. Hayashi, T., Tanaka, K. \& Haruta, M. Selective Vapor-Phase Epoxidation of Propylene over $\mathrm{Au} / \mathrm{TiO}_{2}$ Catalysts in the Presence of Oxygen and Hydrogen. J. Catal. 178, 566-575 (1998).

170. Huang, J., Takei, T., Akita, T., Ohashi, H. \& Haruta, M. Gold clusters supported on alkaline treated TS-1 for highly efficient propene epoxidation with $\mathrm{O}_{2}$ and $\mathrm{H}_{2}$. Appl. Catal. B: Environ. 95, 430-438 (2010).

171. Taylor, B., Lauterbach, J. \& Delgass, W. N. Gas-phase epoxidation of propylene over small gold ensembles on TS-1. Appl. Catal. A: Gen. 291, 188-198 (2005).

172. Wells, D. Formation of hydrogen peroxide from $\mathrm{H}_{2}$ and $\mathrm{O}_{2}$ over a neutral gold trimer: a DFT study. J. Catal. 225, 69-77 (2004).

173. Liu, L., Arenal, R., Meira, D. M. \& Corma, A. Generation of gold nanoclusters encapsulated in an MCM-22 zeolite for the aerobic oxidation of cyclohexane. Chem. Commun. 55, 1607-1610 (2019).

174. Bal, R., Tada, M., Sasaki, T. \& Iwasawa, Y. Direct phenol synthesis by selective oxidation of benzene with molecular oxygen on an interstitial-N/Re cluster/zeolite catalyst. Angew. Chem. Int. Ed. 45, 448-452 (2006).

175. Tada, M. et al. Novel Re-Cluster/HZSM-5 Catalyst for Highly Selective Phenol Synthesis from Benzene and $\mathrm{O}_{2}$ : Performance and Reaction Mechanism. J. Phys. Chem. C 111, 10095-10104 (2007).

176. Beale, A. M., Gao, F., Lezcano-Gonzalez, I., Peden, C. H. \& Szanyi, J. Recent advances in automotive catalysis for NOx emission control by small-pore microporous materials. Chem. Soc. Rev. 44, 7371-7405 (2015).

177. Kwak, J. H. et al. Size-Dependent Catalytic Performance of $\mathrm{CuO}$ on $\gamma-\mathrm{Al}_{2} \mathrm{O}_{3}$ : NO Reduction versus $\mathrm{NH}_{3}$ Oxidation. ACS Catal. 2, 1432-1440 (2012). 
178. Vennestrøm, P. N. R.; Katerinopoulou, A.; Tiruvalam, R. R.; Kustov, A.; Moses, P. G.; Concepcion, P.; Corma, A. Migration of $\mathrm{Cu}$ Ions in SAPO-34 and Its Impact on Selective Catalytic Reduction of NOx with $\mathrm{NH}_{3}$. ACS Catal. 2013, 3, 2158-2161.

179. Paolucci, C.; Khurana, I.; Parekh, A. A.; Li, S.; Shih, A. J.; Li, H.; Di Iorio, J. R.; AlbarracinCaballero, J. D.; Yezerets, A.; Miller, J. T.et al. Dynamic multinuclear sites formed by mobilized copper ions in NOx selective catalytic reduction. Science 2017, 357, 898-903.

180. Liu, A. et al. Controlling Dynamic Structural Transformation of Atomically Dispersed CuOx Species and Influence on Their Catalytic Performances. ACS Catal. 9, 9840-9851 (2019).

181. Martínez-Franco, R.; Moliner, M.; Corma, A. Direct synthesis design of Cu-SAPO-18, a very efficient catalyst for the SCR of NOx. J. Catal. 2014, 319, 36-43.

182. Khivantsev, K.; Jaegers, N. R.; Kovarik, L.; Hanson, J. C.; Tao, F. F.; Tang, Y.; Zhang, X.; Koleva, I. Z.; Aleksandrov, H. A.; Vayssilov, G. N.et al. Achieving Atomic Dispersion of Highly Loaded Transition Metals in Small-Pore Zeolite SSZ-13: High-Capacity and High-Efficiency Low-Temperature CO and Passive NOx Adsorbers. Angew. Chem. Int. Ed. 2018, 57, 16672-16677.

183. Moliner, M.; Corma, A. From metal-supported oxides to well-defined metal site zeolites: the next generation of passive NOx adsorbers for low-temperature control of emissions from diesel engines. React. Chem. Eng. 2019, 4, 223-234.

184. Di Iorio, J. R. et al. The Dynamic Nature of Brønsted Acid Sites in Cu-Zeolites During NOx Selective Catalytic Reduction: Quantification by Gas-Phase Ammonia Titration. Top. Catal. 58, 424-434 (2015).

185. Ye, X. et al. Deactivation of Cu-Exchanged Automotive-Emission $\mathrm{NH}_{3}-\mathrm{SCR}$ Catalysts Elucidated with Nanoscale Resolution Using Scanning Transmission X-ray Microscopy. Angew. Chem. Int. Ed. (2020), doi: 10.1002/anie.201916554.

186. Artioli, N., Lobo, R. F. \& Iglesia, E. Catalysis by Confinement: Enthalpic Stabilization of NO Oxidation Transition States by Micropororous and Mesoporous Siliceous Materials. J. Phys. Chem. C 117, 20666-20674 (2013).

187. Fernández, E. et al. Low-Temperature Catalytic NO Reduction with CO by Subnanometric Pt Clusters. ACS Catal., 11530-11541 (2019).

188. Levasseur, B., Petit, C. \& Bandosz, T. J. Reactive adsorption of $\mathrm{NO}_{2}$ on copper-based metalorganic framework and graphite oxide/metal-organic framework composites. ACS Appl. Mater. Interfaces 2, 3606-3613 (2010).

189. Han, X.; Yang, S.; Schröder, M. Porous metal-organic frameworks as emerging sorbents for clean air. Nat. Rev. Chem. 2019, 3, 108-118.

190. Ghashghaee, M. Heterogeneous catalysts for gas-phase conversion of ethene to higher olefins. Rev. Chem. Eng. 34, 595-655 (2018).

191. Martínez, A., Arribas, M. A., Concepción, P. \& Moussa, S. New bifunctional Ni-H-Beta catalysts for the heterogeneous oligomerization of ethene. Appl. Catal. A: Gen. 467, 509-518 (2013).

192. Moussa, S., Concepción, P., Arribas, M. A. \& Martínez, A. Nature of Active Nickel Sites and Initiation Mechanism for Ethene Oligomerization on Heterogeneous Ni-beta Catalysts. ACS Catal. 8, 3903-3912 (2018).

193. Metzger, E. D.; Brozek, C. K.; Comito, R. J.; Dincă, M. Selective Dimerization of Ethene to 1-Butene with a Porous Catalyst. ACS Cent. Sci. 2016, 2, 148-153.

194. Metzger, E. D.; Comito, R. J.; Hendon, C. H.; Dincă, M. Mechanism of Single-Site Molecule- 
Like Catalytic Ethene Dimerization in Ni-MFU-4l. J. Am. Chem. Soc. 2017, 139, 757-762.

195. Rozhko, E.; Bavykina, A.; Osadchii, D.; Makkee, M.; Gascon, J. Covalent organic frameworks as supports for a molecular Ni based ethene oligomerization catalyst for the synthesis of long chain olefins. J. Catal. 2017, 345, 270-280.

196. Díaz, U.; Corma, A. Ordered covalent organic frameworks, COFs and PAFs. From preparation to application. Coord. Chem. Rev. 2016, 311, 85-124.

197. Hulea, V. Toward Platform Chemicals from Bio-Based Ethene: Heterogeneous Catalysts and Processes. ACS Catal. 8, 3263-3279 (2018).

198. Adam, R. et al. Self-Assembly of Catalytically Active Supramolecular Coordination Compounds within Metal-Organic Frameworks. J. Am. Chem. Soc. 141, 10350-10360 (2019).

199. Thomas, J. M. \& Raja, R. Exploiting nanospace for asymmetric catalysis: confinement of immobilized, single-site chiral catalysts enhances enantioselectivity. Acc. Chem. Res. 41, 708-720 (2008).

200. Chen, Z., Guan, Z., Li, M., Yang, Q. \& Li, C. Enhancement of the performance of a platinum nanocatalyst confined within carbon nanotubes for asymmetric hydrogenation. Angew. Chem. Int. Ed. 50, 4913-4917 (2011).

201. Ma, L., Falkowski, J. M., Abney, C. \& Lin, W. A series of isoreticular chiral metal-organic frameworks as a tunable platform for asymmetric catalysis. Nat. Chem. 2, 838-846 (2010).

202. Xia, Q. et al. Multivariate Metal-Organic Frameworks as Multifunctional Heterogeneous Asymmetric Catalysts for Sequential Reactions. J. Am. Chem. Soc. 139, 8259-8266 (2017).

203. Garcia-Garcia, P., Moreno, J. M., Diaz, U., Bruix, M. \& Corma, A. Organic-inorganic supramolecular solid catalyst boosts organic reactions in water. Nat. Commun. 7, 10835 (2016).

204. Zhang, X., Llabrés i Xamena, F. X. \& Corma, A. Gold(III)-metal organic framework bridges the gap between homogeneous and heterogeneous gold catalysts. J. Catal. 265, 155-160 (2009).

205. Lee, J. S. et al. Architectural Stabilization of a Gold(III) Catalyst in Metal-Organic Frameworks. Chem (2019), doi: 10.1016/j.chempr.2019.10.022.

206. Schejn, A. et al. $\mathrm{Cu}^{2+}$-doped zeolitic imidazolate frameworks (ZIF-8): efficient and stable catalysts for cycloadditions and condensation reactions. Catal. Sci. Technol. 5, 1829-1839 (2015).

207. Zhang, T. \& Lin, W. Metal-organic frameworks for artificial photosynthesis and photocatalysis. Chem. Soc. Rev. 43, 5982-5993 (2014).

208. Liang, Z., Qu, C., Xia, D., Zou, R. \& Xu, Q. Atomically Dispersed Metal Sites in MOF-Based Materials for Electrocatalytic and Photocatalytic Energy Conversion. Angew. Chem. Int. Ed. 57, 9604-9633 (2018).

209. Sastre, F., Fornes, V., Corma, A. \& Garcia, H. Selective, room-temperature transformation of methane to C1 oxygenates by deep UV photolysis over zeolites. J. Am. Chem. Soc. 133, 1725717261 (2011).

210. Li, L. et al. Efficient sunlight-driven dehydrogenative coupling of methane to ethane over a $\mathrm{Zn}^{+}$-modified zeolite. Angew. Chem. Int. Ed. 50, 8299-8303 (2011).

211. Zuo, Q. et al. Ultrathin Metal-Organic Framework Nanosheets with Ultrahigh Loading of Single Pt Atoms for Efficient Visible-Light-Driven Photocatalytic $\mathrm{H}_{2}$ Evolution. Angew. Chem. Int. Ed. 58, 10198-10203 (2019).

212. Liu, X., Inagaki, S. \& Gong, J. Heterogeneous Molecular Systems for Photocatalytic $\mathrm{CO}_{2}$ Reduction with Water Oxidation. Angew. Chem. Int. Ed. 55, 14924-14950, doi:10.1002/anie.201600395 (2016). 
213. Huang, Q. et al. Multielectron transportation of polyoxometalate-grafted metalloporphyrin coordination frameworks for selective $\mathrm{CO}_{2}$-to- $\mathrm{CH}_{4}$ photoconversion. Natl. Sci. Rev., doi:10.1093/nsr/nwz096 (2019).

214. Choi, K. M. et al. Plasmon-Enhanced Photocatalytic $\mathrm{CO}_{2}$ Conversion within Metal-Organic Frameworks under Visible Light. J. Am. Chem. Soc. 139, 356-362 (2017).

215. Sun, L., Campbell, M. G. \& Dinca, M. Electrically Conductive Porous Metal-Organic Frameworks. Angew. Chem. Int. Ed. 55, 3566-3579 (2016).

216. Miner, E. M. et al. Electrochemical oxygen reduction catalysed by $\mathrm{Ni}_{3}$ (hexaiminotriphenylene)2. Nat. Commun. 7, 10942, (2016).

217. Peng, P. et al. A pyrolysis-free path toward superiorly catalytic nitrogen-coordinated single atom. Sci. Adv. 5, eaaw2322, 2322 (2019).

218. Kornienko, N. et al. Metal-organic frameworks for electrocatalytic reduction of carbon dioxide. J. Am. Chem. Soc. 137, 14129-14135 (2015).

219. Lin, S. et al. Covalent organic frameworks comprising cobalt porphyrins for catalytic $\mathrm{CO}_{2}$ reduction in water. Science 349, 1208-1213 (2015).

220. Zheng, W., Liu, M. \& Lee, L. Y. S. Electrochemical Instability of Metal-Organic Frameworks: In Situ Spectroelectrochemical Investigation of the Real Active Sites. ACS Catal. 10, 81-92 (2019).

221. Wu, Y., Jiang, Z., Lu, X., Liang, Y. \& Wang, H. Domino electroreduction of $\mathrm{CO}_{2}$ to methanol on a molecular catalyst. Nature 575, 639-642 (2019).

222. Jahan, M., Bao, Q. \& Loh, K. P. Electrocatalytically active graphene-porphyrin MOF composite for oxygen reduction reaction. J. Am. Chem. Soc. 134, 6707-6713 (2012).

223. Petit, C. \& Bandosz, T. J. MOF-Graphite Oxide Composites: Combining the Uniqueness of Graphene Layers and Metal-Organic Frameworks. Adv. Mater. 21, 4753-4757 (2009).

224. De Luna, P. et al. What would it take for renewably powered electrosynthesis to displace petrochemical processes? Science 364, doi:10.1126/science.aav3506 (2019).

225. Varela, A. S. et al. Electrochemical Reduction of $\mathrm{CO}_{2}$ on Metal-Nitrogen-Doped Carbon Catalysts. ACS Catal. 9, 7270-7284 (2019).

226. Wismann, S. T. et al. Electrified methane reforming: A compact approach to greener industrial hydrogen production. Science 364, 756-759 (2019).

227. Liu, L. et al. Sunlight-assisted hydrogenation of $\mathrm{CO}_{2}$ into ethanol and $\mathrm{C} 2+$ hydrocarbons by sodium-promoted Co@C nanocomposites. Appl. Catal. B: Environ. 235, 186-196 (2018).

228. Thomas, J. M., Johnson, B. F., Raja, R., Sankar, G. \& Midgley, P. A. High-performance nanocatalysts for single-step hydrogenations. Acc. Chem. Res. 36, 20-30 (2003).

229. Sun, J. \& Bao, X. Textural manipulation of mesoporous materials for hosting of metallic nanocatalysts. Chem. Eur. J. 14, 7478-7488 (2008).

230. Cui, T. L. et al. Encapsulating Palladium Nanoparticles Inside Mesoporous MFI Zeolite Nanocrystals for Shape-Selective Catalysis. Angew. Chem. Int. Ed. 55, 9178-9182 (2016).

231. Zhang, J. et al. Sinter-resistant metal nanoparticle catalysts achieved by immobilization within zeolite crystals via seed-directed growth. Nat. Catal. 1, 540-546 (2018).

232. Mielby, J. et al. Oxidation of bioethanol using zeolite-encapsulated gold nanoparticles. Angew. Chem. Int. Ed. 53, 12513-12516 (2014).

233. Park, H. D., Dinca, M. \& Roman-Leshkov, Y. Continuous-Flow Production of Succinic Anhydrides via Catalytic beta-Lactone Carbonylation by $\mathrm{Co}(\mathrm{CO})_{4} \mathrm{Cr}-\mathrm{MIL}-101$. J. Am. Chem. Soc. 
140, 10669-10672 (2018).

234. Lan, G. et al. Metal-Organic Layers as Multifunctional Two-Dimensional Nanomaterials for Enhanced Photoredox Catalysis. J. Am. Chem. Soc. 141, 15767-15772 (2019).

235. Wu, Y. et al. Synergy of Electron Transfer and Electron Utilization via Metal-Organic

Frameworks as an Electron Buffer Tank for Nicotinamide Regeneration. ACS Catal. 10, 2894-2905 (2020).

236. Kingston, C. et al. A Survival Guide for the "Electro-curious". Acc. Chem. Res. 53, 72-83 (2020).

237. Rode, E., Davis, M. E. \& Hanson, B. E. Propylene hydroformylation on rhodium zeolites X and Y I. Catalytic activity. J. Catal. 96, 563-573 (1985).

238. Van $\mathrm{Vu}, \mathrm{T}$. et al. Hydroformylation of olefins over rhodium supported metal-organic framework catalysts of different structure. Microporous Mesoporous Mater. 177, 135-142 (2013).

239. Takahashi, N. Comparison of ethene with propylene hydroformylation over a Rh-Y zeolite catalyst under atmospheric pressure. J. Catal. 85, 89-97 (1984).

240. Zhang, J. et al. Enhancing Regioselectivity via Tuning the Microenvironment in Heterogeneous Hydroformylation of Olefins. J. Catal. (2020), doi: 10.1016/j.jcat.2020.03.032.

241. Sun, Q. et al. Highly Efficient Heterogeneous Hydroformylation over Rh-Metalated Porous Organic Polymers: Synergistic Effect of High Ligand Concentration and Flexible Framework. $J$. Am. Chem. Soc. 137, 5204-5209 (2015).

242. Li, C. et al. Single atom dispersed Rh-biphephos\&PPh ${ }_{3} @$ porous organic copolymers: highly efficient catalysts for continuous fixed-bed hydroformylation of propene. Green Chem. 18, 29953005 (2016).

243. Corma, A. Heterogeneous Catalysis: Understanding for Designing, and Designing for Applications. Angew. Chem. Int. Ed. 55, 6112-6113 (2016).

244. Gallego, E. M. et al. "Ab initio" synthesis of zeolites for preestablished catalytic reactions. Science 355, 1051-1054 (2017).

245. Li, C. et al. Synthesis of reaction-adapted zeolites as methanol-to-olefins catalysts with mimics of reaction intermediates as organic structure-directing agents. Nat. Catal. 1, 547-554 (2018).

246. Gallego, E. M., Paris, C., Cantín, Á., Moliner, M. \& Corma, A. Conceptual similarities between zeolites and artificial enzymes. Chem. Sci. doi:10.1039/c9sc02477h (2019).

247. Zecevic, J., Vanbutsele, G., de Jong, K. P. \& Martens, J. A. Nanoscale intimacy in bifunctional catalysts for selective conversion of hydrocarbons. Nature 528, 245-248 (2015).

248. Bayram, E. et al. Agglomerative Sintering of an Atomically Dispersed $\operatorname{Ir}_{1} /$ Zeolite Y Catalyst: Compelling Evidence Against Ostwald Ripening but for Bimolecular and Autocatalytic Agglomeration Catalyst Sintering Steps. ACS Catal. 5, 3514-3527 (2015).

249. Serna, P. \& Gates, B. C. Zeolite-supported rhodium complexes and clusters: switching catalytic selectivity by controlling structures of essentially molecular species. J. Am. Chem. Soc. 133, 4714-4717 (2011).

250. Wei, Y., Parmentier, T. E., de Jong, K. P. \& Zecevic, J. Tailoring and visualizing the pore architecture of hierarchical zeolites. Chem. Soc. Rev. 44, 7234-7261 (2015).

251. Furukawa, H., Muller, U. \& Yaghi, O. M. "Heterogeneity within order" in metal-organic frameworks. Angew. Chem. Int. Ed. 54, 3417-3430 (2015).

252. Perez-Ramirez, J., Christensen, C. H., Egeblad, K., Christensen, C. H. \& Groen, J. C. 
Hierarchical zeolites: enhanced utilisation of microporous crystals in catalysis by advances in materials design. Chem. Soc. Rev. 37, 2530-2542 (2008).

253. Čejka, J. \& Mintova, S. Perspectives of Micro/Mesoporous Composites in Catalysis. Catal. Rev. 49, 457-509 (2007).

254. Mintova, S., Jaber, M. \& Valtchev, V. Nanosized microporous crystals: emerging applications. Chem. Soc. Rev. 44, 7207-7233 (2015).

255. Stock, N. \& Biswas, S. Synthesis of metal-organic frameworks (MOFs): routes to various MOF topologies, morphologies, and composites. Chem. Rev. 112, 933-969 (2012).

256. Diaz, U., Brunel, D. \& Corma, A. Catalysis using multifunctional organosiliceous hybrid materials. Chem. Soc. Rev. 42, 4083-4097 (2013). 
a

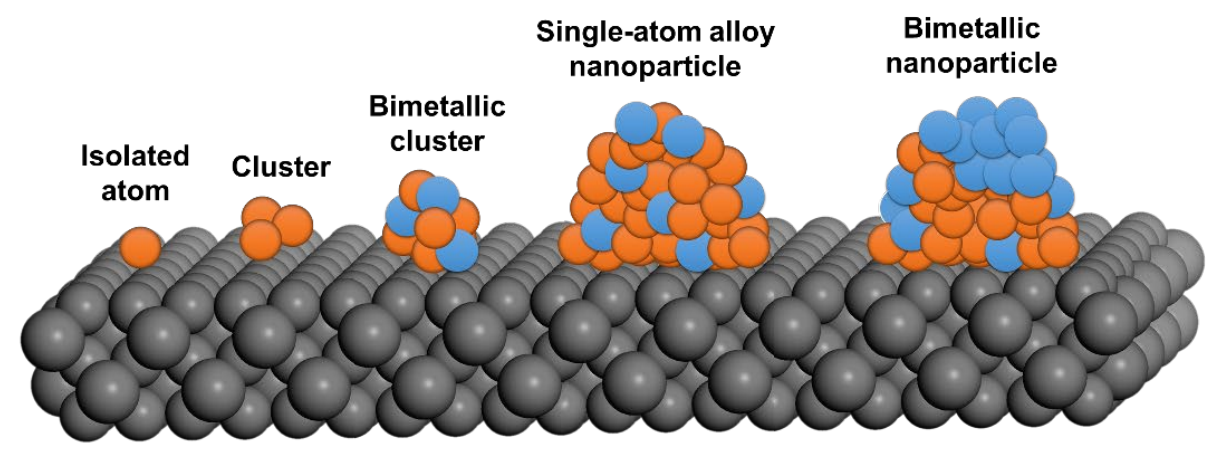

b

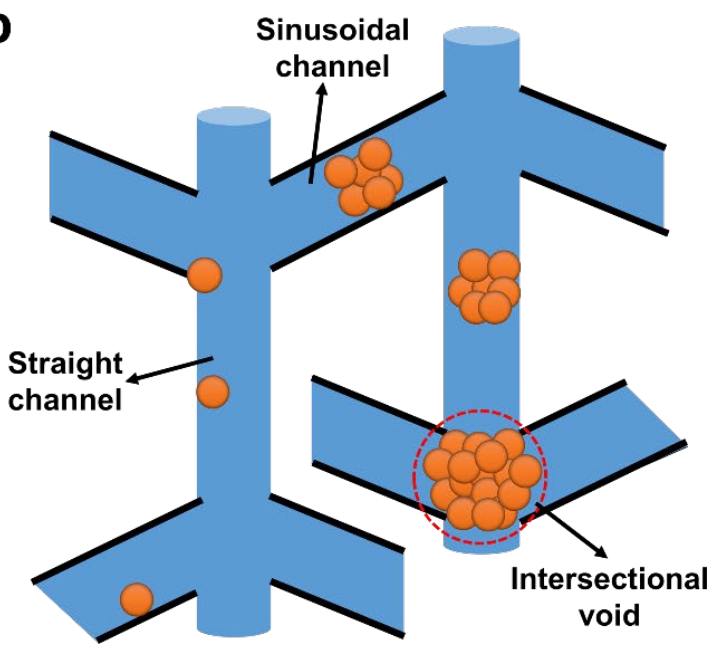

C Metal bonded to inorganic node

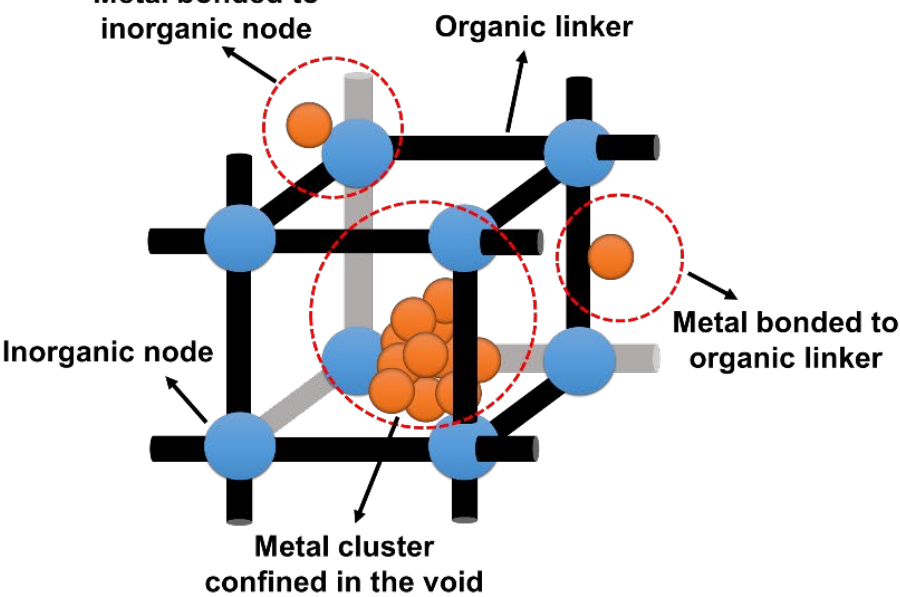

Figure 1. Schematic illustration of isolated atoms and subnanometric metal clusters supported on conventional solid carriers (a), confined in zeolite (MFI-type zeolite as an example) (b) and metal-organic framework (c). In (a), several typical metal species from isolated metal atoms to bimetallic nanoparticles supported on open-structure solid carriers are illustrated. In (b) and (c), isolated metal atoms and clusters located in different positions within the microporous crystalline materials (zeolites and MOFs) are illustrated. Notice that, we will be reviewing here about transition metal atoms that do not occupy the tetrahedral coordination positions in the zeolite framework (e.g. Ga, Fe, Ti, Sn, etc.). Instead, we will discuss basically about isolated transition metal atoms and nanoclusters, such as $\mathrm{Ni}, \mathrm{Co}, \mathrm{Cu}, \mathrm{Pt}, \mathrm{Pd}, \mathrm{Rh}$, Ir, etc., due to their strong impacts in catalysis as extra-framework species in zeolites and MOFs. 
a
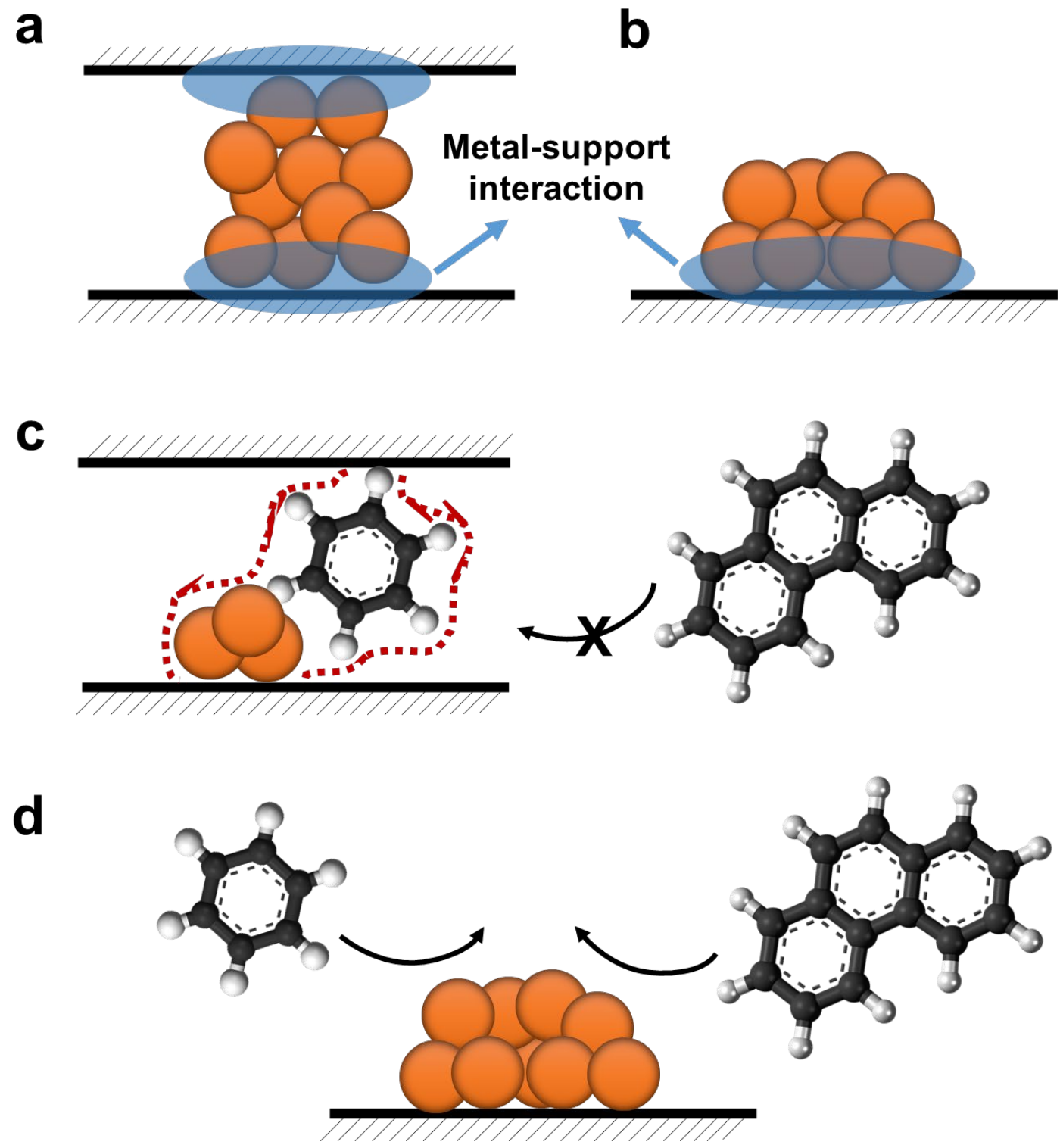

Figure for Box 1. Confinement effect on supported metal catalysts. (a) Subnanometric metal cluster confined in microporous materials (zeolites or MOFs). Interaction between the metal clusters and the microporous framework exists at the interface. (b) Subnanometric metal cluster supported on conventional open-structure solid carriers. (c) Small metal cluster confined in microporous materials. When the size of the metal species is smaller than the cavity within the microporous matrix, the confinement effect is not as strong as the larger metal species. However, by considering the combination of the metal entity and the reactant, the porous matrix can influence the metal-reactant interaction and therefore the catalytic reactivity. Furthermore, as a result of molecular sieving effect, reactants larger than the pore size will not have access to the confined metal entity. (d) Metal particle supported on conventional open-structure solid carrier. Both small and large reactants can have access 
to the metal entity. According to the particle size, heterogeneous metal catalysts can be divided into three types: isolated metal atoms (usually transition metals), metal clusters with a few atoms (usually below $1 \mathrm{~nm}$ ) and metal nanoparticles ( $>1 \mathrm{~nm}$, normally with $>20$ atoms). In this review, we are focused on subnanometric metal entities (isolated metal atoms and metal clusters) encapsulated inside the crystalline microporous materials (with pore size below $2 \mathrm{~nm}$ ), such as zeolites and MOFs. Taking metal-zeolite material as an example, the encapsulation of a metal cluster in zeolite crystallite refers to anchoring the metal cluster in the pore or cavity of the zeolite structure. The stabilization of metal species in zeolites is mainly achieved by forming bonding between the metal species and framework O. Since the contact area between the metal species and the framework could be larger than the scenario with conventional supported metal catalyst, the interaction can be stronger. The mobility of the metal entities is limited by the framework and their structures (electronic and geometric structures) will also be influenced. Furthermore, the molecular sieving effect from the crystalline microporous framework also affects the accessibility of the encapsulated metal species. 
a Impregnation

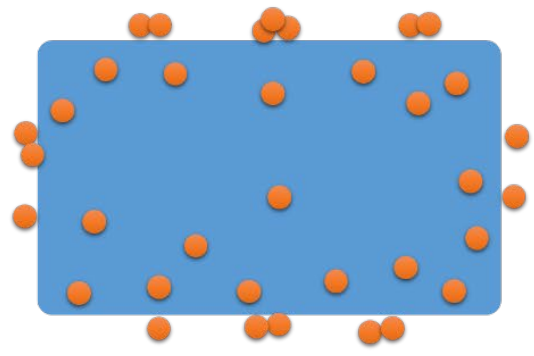

High-temperature oxidationreduction treatment

b Ion-exchange

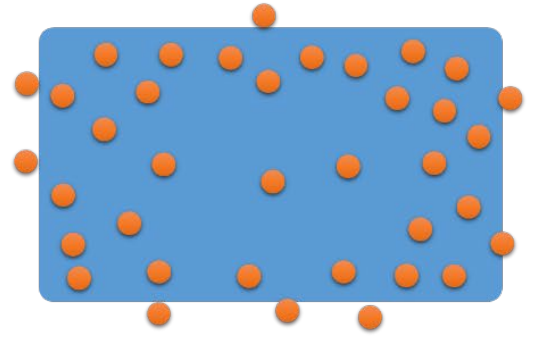

High-temperature oxidationreduction treatment
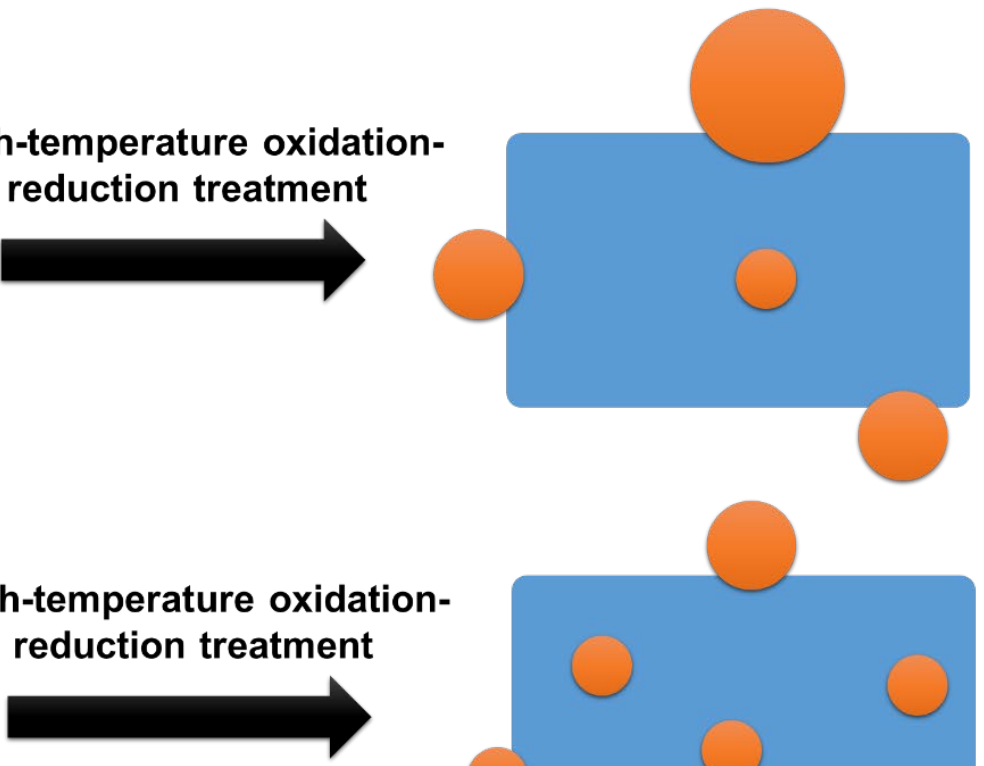

C One-pot synthesis

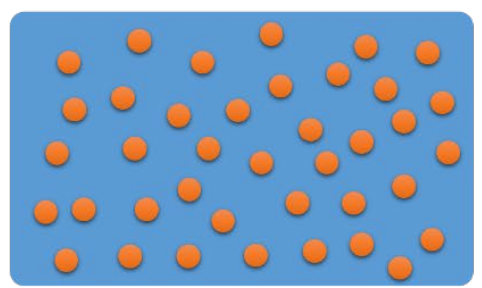

\section{High-temperature oxidation- reduction treatment

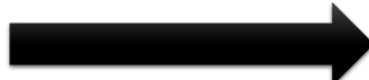

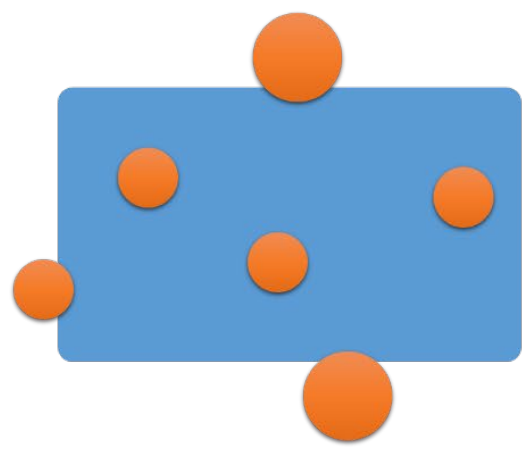

Figure 2. Introduction of metal catalysts in zeolite crystallites by different methods. (a) Conventional impregnation, (b) ion-exchange method and (c) one-pot synthesis. For instance, using $\left[\mathrm{Pt}\left(\mathrm{NH}_{3}\right)_{4}\right]^{2+}$ complex as precursor, isolated Pt atoms can be easily introduced into zeolite $\mathrm{Y}$ by exchanging with the protons in zeolite framework due to the presence of Al(III) framework sites. However, the Pt complex will decompose and form Pt-O bonding with the zeolite framework during the subsequent heating treatment. Meantime, part of the Pt species will sinter into nanoparticles during the decomposition of $\left[\mathrm{Pt}\left(\mathrm{NH}_{3}\right)_{4}\right]^{2+}$ complex. In the case of impregnation, by mixing the zeolite support with precursor solution and subsequent removal of the solvent, metal precursor can be loaded on the zeolite support. When the metal-zeolite material is prepared by impregnation or ion-exchange process, the majority of the metal species is located on the surface or near-surface areas, which will agglomerate into large particles in subsequent high-temperature oxidation-reduction treatments. While in the case of metal-zeolite material prepared by one-pot synthesis, the stability is greatly enhanced due to the good encapsulation of metal entities by the zeolite framework, suppressing their sintering. 

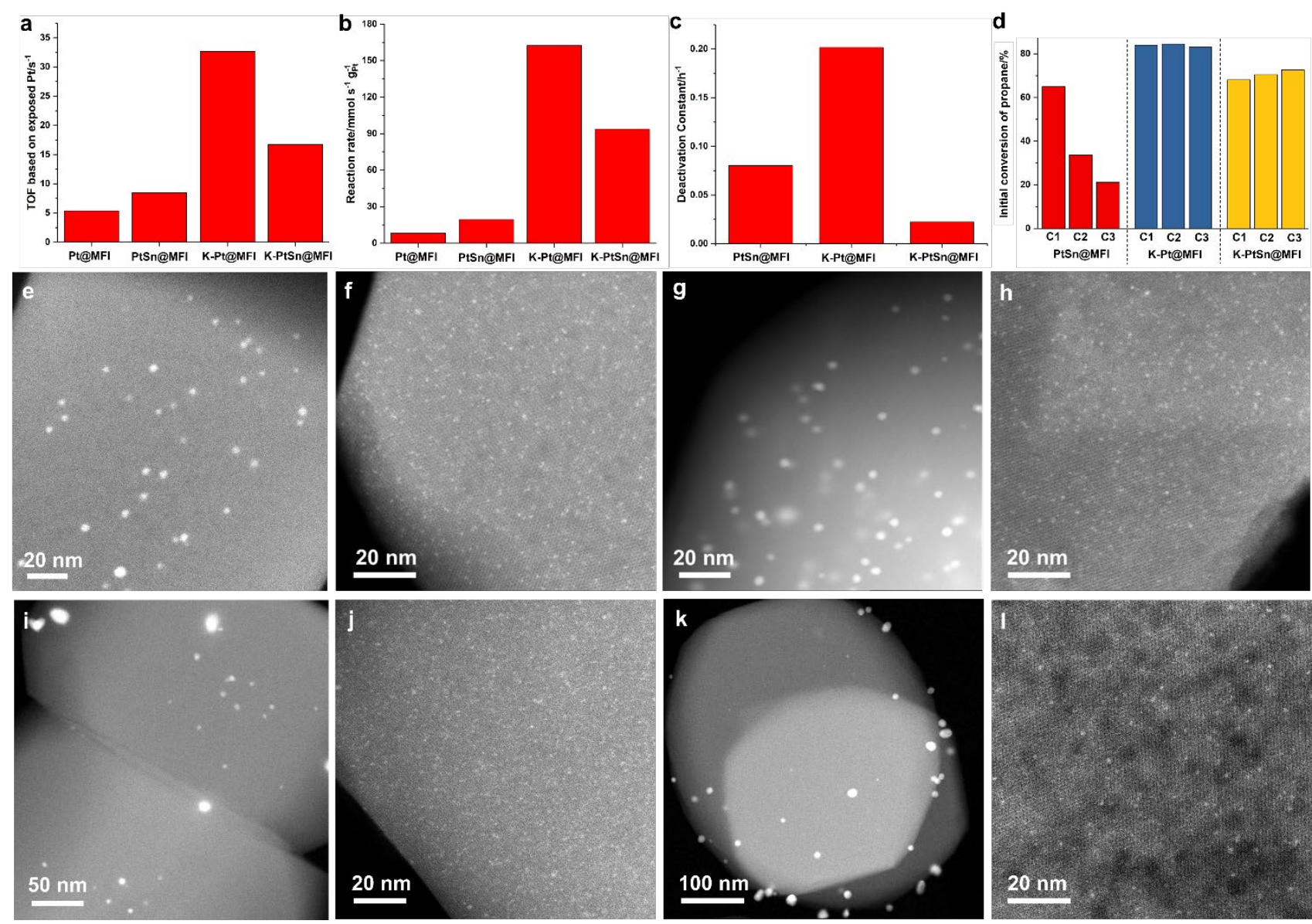

Figure 3. Catalytic performance of Pt-MFI materials for propane dehydrogenation reaction. (a)

Initial turnover frequency (TOF) of various Pt-zeolite materials for propane dehydrogenation reaction at $600{ }^{\circ} \mathrm{C}$ based on the exposed Pt sites determined by the average particle size derived from electron microscopy and EXAFS results. The TOF values were calculated based on the initial propane conversion at kinetic regime (conversion below $<20 \%$ ) at $600{ }^{\circ} \mathrm{C}$. (b) Initial reaction rates of various Pt-zeolite materials for propane dehydrogenation reaction at $600{ }^{\circ} \mathrm{C}$ based on the mass of $\mathrm{Pt}$ in the solid catalyst. From a practical point of view, the initial reaction rate based on the mass of Pt species will be more meaningful for the evaluation of their catalytic performance. As can be seen in (b), the K-containing Pt-zeolite samples (K-Pt@MFI and K-PtSn@MFI) show much higher initial reaction rate than the $\mathrm{K}$-free samples, indicating the significant promotion effect of $\mathrm{K}$ and higher reactivity of subnanometric Pt clusters. (c) Deactivation constant of PtSn@MFI, K-Pt@MFI and K-PtSn@MFI samples in the first $10 \mathrm{~h}$ during the first catalytic cycle of propane dehydrogenation reaction. calculated from the following equation: $\ln \left[\left(1-\mathrm{X}_{\text {final }}\right) / \mathrm{X}_{\text {final }}\right]=\mathrm{k}_{\mathrm{d}} * \mathrm{t}+\ln \left[\left(1-\mathrm{X}_{\text {intial }}\right) / \mathrm{X}_{\text {intial }}\right]$, where $\mathrm{X}$ corresponds to the conversion of propane. (d) Initial propane conversion on PtSn@MFI, K-Pt@MFI and K- 
PtSn@MFI catalysts in different catalytic cycles. The initial conversion of propane decreases significantly when the K-free PtSn@MFI sample is regenerated for the second and third catalytic test, which is caused by the sintering of Pt. Notably, both K-Pt@MFI and K-PtSn@MFI show good recyclability in three consecutive reaction-regeneration cycles, indicating the high stability of subnanometric Pt clusters confined in the sinusoidal 10MR channels. (e-h) HAADF-STEM images of various pristine Pt-MFI catalysts after reduction by $\mathrm{H}_{2}$ at $600{ }^{\circ} \mathrm{C}$. (e) Pt@MFI, (f) K-Pt@MFI, (g) PtSn@MFI and (h) K-PtSn@MFI. (i-1) HAADF-STEM images of various pristine Pt-MFI catalysts after propane dehydrogenation reaction. (i) Pt@MFI, (j) K-Pt@MFI, (k) PtSn@MFI and (1) KPtSn@MFI. By comparing the size of Pt particles in the pristine and used catalyst, the sintering of Pt nanoparticles in the K-free samples is clearly observed. While in the K-promoted samples, subnanometric Pt clusters can be preserved after the catalytic tests for propane dehydrogenation reaction. Images adapted from Ref. 73. 

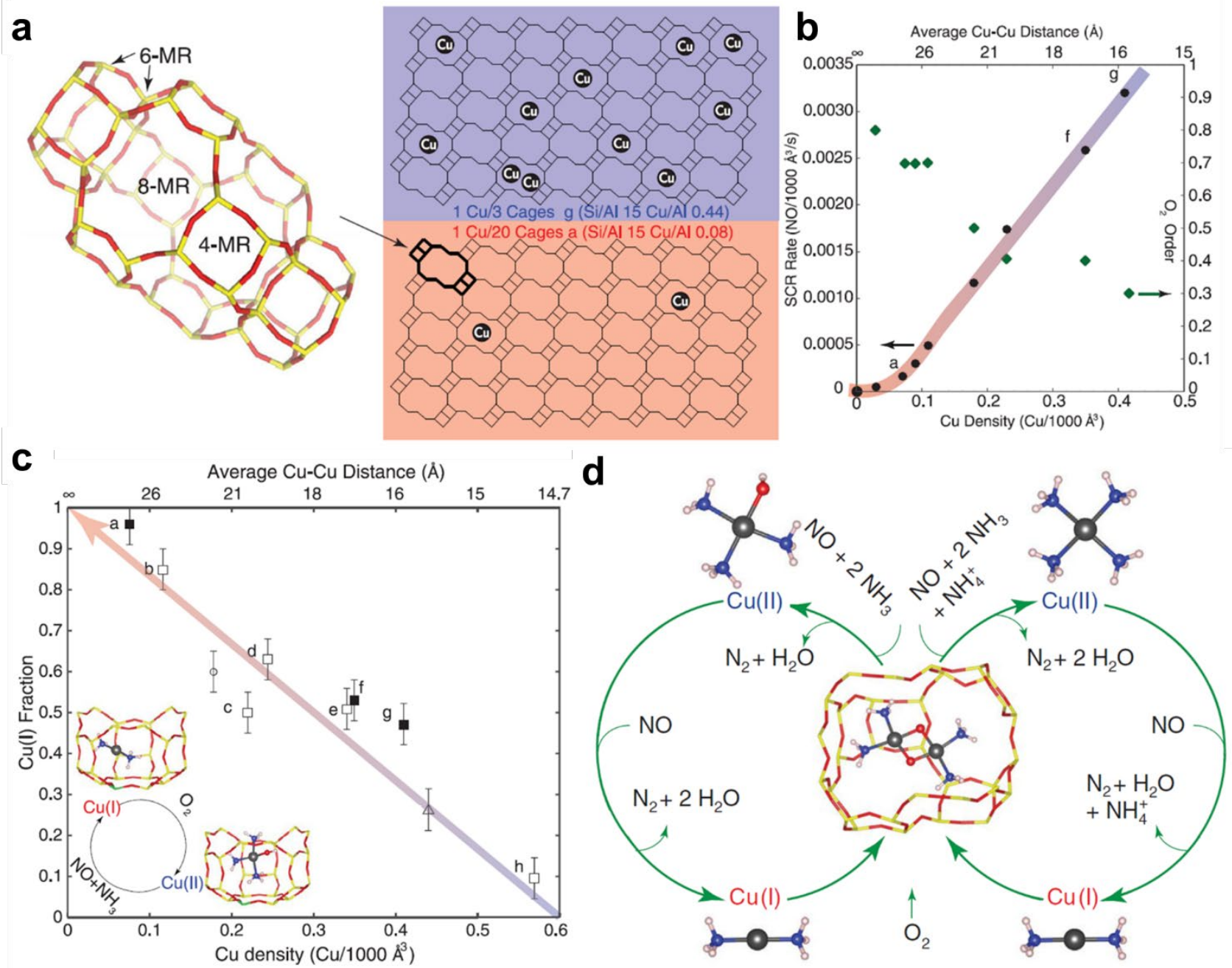

Figure 4. Influence of the density of Cu species in CHA zeolite on NOx-SCR activity. (A) The CHA cage and schematic representation of the $\mathrm{Cu}$ ion densities per CHA cage. (B) Standard NOx-SCR reaction rates and apparent $\mathrm{O}_{2}$ orders measured with $\mathrm{Cu}-\mathrm{CHA}$ samples $(\mathrm{Si} / \mathrm{Al}=15)$ when increasing the density of $\mathrm{Cu}$ ions in $\mathrm{CHA}$ zeolite. (C) The dependence of $\mathrm{Cu}^{\mathrm{I}}$ fraction on $\mathrm{Cu}$ ion volumetric density during steady-state standard NOx-SCR reaction at $473 \mathrm{~K}$, measured by XANES. As shown in (a) and (b), the SCR activity increases linearly with the $\mathrm{Cu}$ density in CHA zeolite when the $\mathrm{Cu}$ density is higher than $1.9 \times 10^{-4} \AA^{-3}$, which is consistent with the literature. However, when the $\mathrm{Cu}$ density decreases to below $1.13 \times 10^{-4} \AA^{-3}$, the SCR reaction rate varies quadratically with the $\mathrm{Cu}$ density. Furthermore, the chemical state of $\mathrm{Cu}$ species is also dependent on the $\mathrm{Cu}$ volumetric density (c). (d) Proposed low-temperature SCR catalytic cycle. Reduction steps proceed on site-isolated $\mathrm{Cu}^{\mathrm{II}}$ ions residing near one (left-hand cycle) or two (right-hand cycle) framework Al centers with constrained diffusion of $\mathrm{Cu}^{\mathrm{I}}$ ions into single cages and oxidation by $\mathrm{O}_{2}$ (inner step). Adapted with permission from Ref. 179. Copyright 2017 AAAS. 

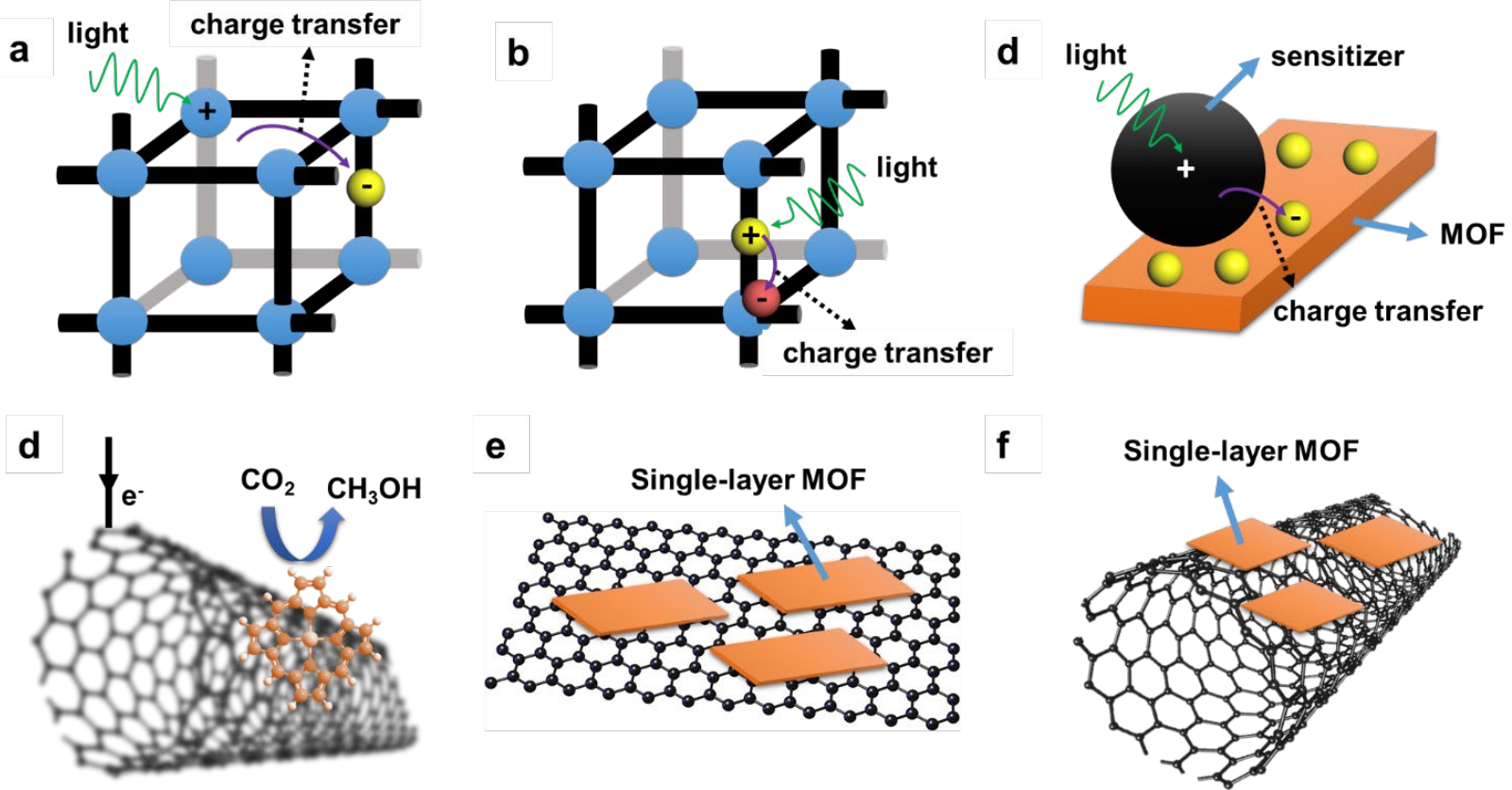

Figure 5. Subnanometric metal species confined in MOF for photocatalysis and electrocatalysis. The photo-generated charge carriers (holes and electrons) can be generated in various ways and then transferred to the metal sites confined in MOF for photocatalytic reactions. (a) Isolated metal atom or cluster serves as the co-catalyst to host the photo-generated charge carrier generated in the MOF framework structure. (b) Light is absorbed by a photo-sensitizer and the photo-generated charge carrier is subsequently transferred to a neighboring metal site. (c) Photo-generated charge carrier is generated in a photo-sensitizer material (e.g. semiconductor, plasmonic metal particle) and then transferred to MOF consisting of subnanometric metal species. (d) Molecular cobalt phthalocyanine catalyst supported on carbon nanotubes for the electrocatalytic $\mathrm{CO}_{2}$ reduction to methanol. (e, f) Proposed catalyst comprising single-layer metal phthalocyanine MOF on graphene and carbon nanotubes. 

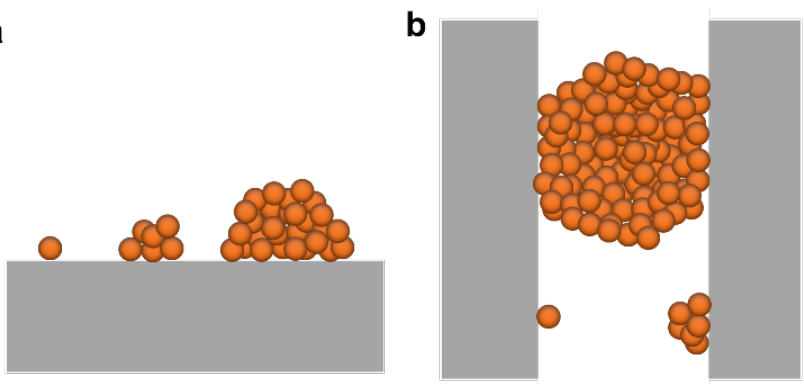

e

\begin{tabular}{c|ccc}
\hline Catalyst structure & $\begin{array}{c}\text { Confinement } \\
\text { effect }\end{array}$ & Stability & Shape-selectivity \\
\hline $\begin{array}{c}\text { Metal entities on open- } \\
\text { structure support }\end{array}$ & None & Low & None \\
\hline $\begin{array}{c}\text { Metal nanoparticles } \\
\text { supported on } \\
\text { mesoporous support }\end{array}$ & Limited & Moderate & Limited \\
\hline $\begin{array}{c}\text { Isolated atoms and } \\
\text { clusters confined in } \\
\text { microporous materials }\end{array}$ & Yes & High & Yes \\
\hline $\begin{array}{c}\text { Metal nanoparticles } \\
\text { encapsulated in } \\
\text { mesoporous materials }\end{array}$ & Moderate & High & Yes \\
\hline
\end{tabular}

c
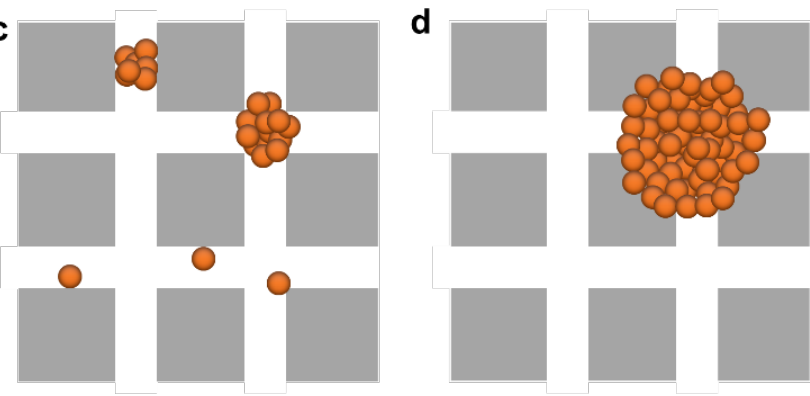

\begin{tabular}{|c|c|c|}
\hline Catalytic property & $\begin{array}{l}\text { Metal entities confined } \\
\text { in Zeolites }\end{array}$ & $\begin{array}{c}\text { Metal entities } \\
\text { confined in MOFs }\end{array}$ \\
\hline Stability & High & Low \\
\hline Confinement effect & Strong & Moderate \\
\hline Reaction substrate scope & $\begin{array}{c}\text { Activation of small } \\
\text { molecules }\left(\mathrm{H}_{2}, \mathrm{O}_{2}, \mathrm{CO}\right. \\
\mathrm{CO}_{2} \text {, light } \\
\text { hydrocarbons...) }\end{array}$ & $\begin{array}{l}\text { More suitable for } \\
\text { reactions involving } \\
\text { organic molecules }\end{array}$ \\
\hline Reaction scope & $\begin{array}{c}\text { Widely used for } \\
\text { conventional thermal } \\
\text { catalysis }\end{array}$ & $\begin{array}{l}\text { More suitable for } \\
\text { reaction under mild } \\
\text { conditions. } \\
\text { Advantages in } \\
\text { electrocatalysis and } \\
\text { photocatalysis }\end{array}$ \\
\hline
\end{tabular}

Figure 6. Comparison of different types of supported metal catalysts. (a) Metal catalysts supported on open-structure solid carriers. (b) Metal particles located in mesoporous materials with pore size $\geq 2 \mathrm{~nm}$. (c) Isolated metal atoms and subnanometric metal clusters confined in microporous materials with pore size below $2 \mathrm{~nm}$. (d) Metal nanoparticles encapsulated in microporous materials. In this scenario, the size of the metal particle is larger than the pore size. As a result, the porous structure surrounding the metal particle could be partially distorted. (e) Influence of the support and catalyst morphology on the catalytic performance of various heterogeneous metal catalysts in terms of confinement effect, stability and shape-selectivity. (f) Comparison of subnanometric metal catalysts confined in zeolites and MOFs. 
Table 1. Characterization techniques for isolated metal atoms and clusters in porous materials.

\begin{tabular}{|c|c|c|c|c|c|c|c|}
\hline Technique & $\begin{array}{c}\text { Morphology } \\
\text { (Shape, } \\
\text { size...) }\end{array}$ & $\begin{array}{c}\text { Atomic } \\
\text { resolution }\end{array}$ & $\begin{array}{l}\text { Chemical } \\
\text { composition }\end{array}$ & $\begin{array}{c}\text { Surface } \\
\text { sensitivity }\end{array}$ & $\begin{array}{l}\text { Electronic } \\
\text { properties }\end{array}$ & $\begin{array}{l}\text { Coordination } \\
\text { environment }\end{array}$ & $\begin{array}{l}\text { Local } \\
\text { /Bulk }\end{array}$ \\
\hline $\begin{array}{c}\text { S/TEM } \\
\text { EELS/EDS }\end{array}$ & $Y$ & $Y$ & $Y$ & $\mathrm{~N}$ & $\mathrm{~N}$ & $\mathrm{~N}$ & Local \\
\hline APT & Y & Y & Y & $\mathrm{N}$ & $\mathrm{N}$ & $\mathrm{N}$ & Local \\
\hline EXAFS/XANES & Y & $\mathrm{N}$ & Y & $\mathrm{N}$ & $\mathrm{N}$ & Y & Bulk \\
\hline $\begin{array}{c}\text { UV } \\
\text { Fluorescence }\end{array}$ & $\mathrm{N}$ & $\mathrm{N}$ & $\mathrm{N}$ & $\mathrm{N}$ & $Y$ & $\mathrm{~N}$ & Bulk \\
\hline IR & $\mathrm{N}$ & $\mathrm{N}$ & $\mathrm{N}$ & $\mathrm{N}$ & Y & $Y$ & Bulk \\
\hline ssNMR & $\mathrm{N}$ & $\mathrm{N}$ & $\mathrm{N}$ & $\mathrm{N}$ & Y & $Y$ & Bulk \\
\hline XPS & $\mathrm{N}$ & $\mathrm{N}$ & $Y$ & Y & $Y$ & $\mathrm{~N}$ & Bulk \\
\hline
\end{tabular}

Note: $\mathrm{Y}$, feasible to obtain the information; $\mathrm{N}$, not feasible to obtain the information. 